OPEN ACCESS

Edited by:

Olivier Girard

Murdoch University, Australia

Reviewed by:

Ryu Nagahara,

National Institute of Fitness and

Sports in Kanoya, Japan

Jean Slawinski,

Institut National du Sport, de

l'Expertise et de la

Performance, France

*Correspondence:

Athanassios Bissas

a.bissas@athleticsbiomechanics.com

tPresent address: Athanassios Bissas,

Athletics Biomechanics, Leeds, United Kingdom

Specialty section

This article was submitted to

Elite Sports and Performance

Enhancement,

a section of the journal

Frontiers in Sports and Active Living

Received: 20 June 2019

Accepted: 27 August 2019

Published: 18 September 2019

Citation:

Bezodis IN, Brazil A, von Lieres und Wilkau HC, Wood MA, Paradisis GP,

Hanley B, Tucker CB, Pollitt $L$

Merlino S, Vazel P-J, Walker J and Bissas A (2019) World-Class Male

Sprinters and High Hurdlers Have Similar Start and Initial Acceleration Techniques.

Front. Sports Act. Living 1:23 doi: 10.3389/fspor.2019.00023

\section{World-Class Male Sprinters and High Hurdlers Have Similar Start and Initial Acceleration Techniques}

\author{
lan N. Bezodis ${ }^{1}$, Adam Brazil ${ }^{2}$, Hans C. von Lieres und Wilkau ${ }^{1}$, Matthew A. Wood ${ }^{1}$, \\ Giorgios P. Paradisis ${ }^{3}$, Brian Hanley ${ }^{4}$, Catherine B. Tucker ${ }^{4}$, Lysander Pollitt ${ }^{4}$, \\ Stéphane Merlino ${ }^{5}$, Pierre-Jean Vazel ${ }^{6}$, Josh Walker ${ }^{4}$ and Athanassios Bissas ${ }^{4 * t}$ \\ ${ }^{1}$ Cardiff School of Sport and Health Sciences, Cardiff Metropolitan University, Cardiff, United Kingdom, ${ }^{2}$ Department for \\ Health, University of Bath, Bath, United Kingdom, ${ }^{3}$ Athletics Sector, School of Physical Education and Sport Science, \\ National and Kapodistrian University of Athens, Athens, Greece, ${ }^{4}$ Carnegie School of Sport, Leeds Beckett University, Leeds, \\ United Kingdom, ${ }^{5}$ Development Department, International Association of Athletics Federations, Monaco City, Monaco, \\ ${ }^{6}$ Athlétisme Metz Métropole, Metz, France
}

The effect of the inclusion of a high hurdle $13.72 \mathrm{~m}$ after the start line on elite sprint start and initial acceleration technique has yet to be investigated or understood. This highly novel study addresses that lack of information in an exceptional manner, through detailed biomechanical analysis of the world's best sprint and hurdle athletes, with data collected in situ at the 2018 IAAF World Indoor Championships, held in Birmingham, UK. High speed videos $(150 \mathrm{~Hz})$ were compared for eight sprinters and seven hurdlers for the start and initial acceleration phase of the finals of the men's $60 \mathrm{~m}$ and $60 \mathrm{~m}$ hurdles. Temporal and kinematic data were supplemented by vector coding analysis to investigate mechanisms by which these world-class athletes translate their centres of mass (CM) up to the fourth touchdown post-block exit. The sprinters and hurdlers coordinated their lower limb and trunk movement in a similar manner throughout the start and initial acceleration phases, which contributes new conceptual understanding of the mechanisms that underpin start and initial acceleration performance. Differences between groups were initiated from block set-up, with the hurdlers utilising a larger block spacing, but with the front block nearer to the start line than sprinters. Even after accounting for stature, the biggest differences in the raising of the CM occurred during the block phase, with hurdlers greater than sprinters (difference in vertical CM displacement scaled to stature $=-0.037$, very large effect size). Subsequent flight phases showed the biggest differences in the translation of the $\mathrm{CM}$, in part due to longer flight times in the hurdlers, whilst the techniques of the two groups generally converged during the ground contact phases of initial acceleration. In highlighting that similar techniques are used by world-class sprinters and hurdlers, despite differing task constraints, this study has provided invaluable insights for scientists, coaches, and athletes, that will inform further developments in understanding and practice across both sprints and hurdles.

Keywords: acceleration, biomechanics, coordination, hurdles, kinematics, sprint start, track and field, world championships 


\section{INTRODUCTION}

Although it is well-established that effective maximal sprint acceleration is dependent on primarily horizontal external kinetics (Morin et al., 2011; Rabita et al., 2015) and matching segmental kinematics (Kugler and Janshen, 2010; Nagahara et al., 2014; von Lieres und Wilkau et al., 2018), research has not examined what effect the inclusion of a high hurdle has on acceleration performance and centre of mass (CM) projection. To the authors' knowledge the only published works investigating the initial acceleration phase in sprint hurdlers have been confined to a simple spatio-temporal analysis (Rash et al., 1990) and a single athlete case study covering kinematics, external kinetics, and electromyography (Coh et al., 2007) in female athletes, for whom the hurdles are $0.838 \mathrm{~m}$ high. For male high hurdlers, the placement of a $1.067 \mathrm{~m}$ high hurdle $13.72 \mathrm{~m}$ from the start line introduces an additional task constraint. This is yet to be investigated in terms of its effect on performance in the start and initial acceleration phase, which are critical to optimal overall performance. The initial acceleration phase has previously been defined as lasting four to six steps after block exit (Nagahara et al., 2014; von Lieres und Wilkau et al., 2018).

A key characteristic of a hurdler's approach to the first hurdle is the number of steps taken, which in recent years has shifted to a seven-step pattern among the world's elite. However, the coaching literature has suggested both seven (Freeman, 2015) and eight step approaches (Mann and Murphy, 2018) as closer to initial acceleration mechanics in sprinters. The absence of an examination of initial acceleration mechanics in high hurdles and a detailed comparison of sprint and hurdle start and initial acceleration has important implications for both coach and athlete development as well as the understanding of optimal performance.

The word "elite" is overused in sports science literature, and the number of published studies on the biomechanics of the world's best able-bodied sprinters is small. Out-of-competition data have been presented from the block start (Bezodis et al., 2015; Willwacher et al., 2016), initial acceleration phase (Wild et al., 2018), composite $40 \mathrm{~m}$ maximal acceleration (Rabita et al., 2015), maximum velocity phase (Bezodis et al., 2008, 2018), and a full $100 \mathrm{~m}$ sprint (Morin et al., 2012) of groups of athletes that generally contained one sub-10s sprinter. There are also examples of analyses of elite $100 \mathrm{~m}$ races based primarily on distance-time data, either taken from broadcast television footage or data from previous IAAF biomechanics projects (e.g., Salo et al., 2011; Taylor and Beneke, 2012; Slawinski et al., 2017). However, to the authors' knowledge, more detailed kinematic analyses of elite athletes in competition are confined to the block and initial acceleration phase from a Diamond League $100 \mathrm{~m}$ final (Ciacci et al., 2017) and the home straight of the 1984 Olympic $200 \mathrm{~m}$ final (Mann and Herman, 1985b). Lately, the IAAF has published detailed biomechanical reports from both outdoor and indoor World Championships (Bissas et al., 2018; Pollitt et al., 2018; Walker et al., 2019a,b). However, the lack of peer-reviewed analysis of "world-class sprinters (e.g., international finalists)" has very recently been highlighted in a comprehensive review of the biomechanics of the sprint start as a major gap in the research literature (Bezodis et al., 2019b).

The inherent nature of biomechanical data collection with elite athletes in competition necessitates an approach that minimises interference with the athletes. This usually means that studies conducted in these settings have to focus on kinematic analyses (e.g., Mann and Herman, 1985a,b; Ciacci et al., 2017). Studies of sub-elite athletes have demonstrated that segmental orientations closely reflect the external force characteristics that are important for effective maximal sprint acceleration (Kugler and Janshen, 2010; Nagahara et al., 2014; von Lieres und Wilkau et al., 2018). Therefore, kinematic analyses can play an important role in improving the understanding of the mechanisms that underpin effective sprint start and acceleration performance. The role of the trunk segment during the block phase (Slawinski et al., 2012), and of the shank and trunk segments during the initial acceleration phase (von Lieres und Wilkau et al., 2018) have been shown to be important for efficient performance. At a joint kinetic level in the initial acceleration phase, the ankle plantarflexors and hip extensors are important energy generators (Charalambous et al., 2012; Bezodis et al., 2014; Brazil et al., 2017), whilst the magnitude of knee extensor energy generation is thought to relate to sprint performance (Debaere et al., 2013; Bezodis et al., 2014; Brazil et al., 2018).

Studies of the block and initial acceleration phases of sprinters have shown mechanisms by which they project their CM to address the task. Debaere et al. (2013) reported horizontal and vertical block exit velocities of 3.10 and $0.84 \mathrm{~m} / \mathrm{s}$, respectively. Whereas the horizontal velocity increased in a relatively consistent linear manner throughout the block phase, the vertical velocity increased rapidly through the initial double-leg push phase, peaking at $0.74 \mathrm{~m} / \mathrm{s}$, and then only showing a small further increase up to block exit. This suggests that there is an equal focus on both forward and upward projection of the CM during the double-leg push phase, but that this switches to a primary focus on the forward projection of the CM during the single-leg push phase. Characteristics of external force data gathered during the block phase support this suggestion (Willwacher et al., 2016; Bezodis et al., 2019a), and it has previously been shown that rearleg force production in the blocks is a key discriminant of sprint performance in athletes ranging from national level to worldclass (Fortier et al., 2005; Willwacher et al., 2016; Brazil et al., 2018).

The assessment of coordination offers an advancement beyond single-joint kinematic analysis to understand sports technique, offering insight into the interaction between components of the biological system that are functionally linked to satisfy the demands of a given task (Bernstein, 1967; Turvey, 1990). The theoretical model of constraints on action (Newell, 1986) describes how individuals adopt movement coordination patterns via self-organisation within the context of organismic, environmental and task related constraints imposed on the biological system. These coordination patterns are commonly assessed through investigating the relative motion between joints or segments of the same limb, providing a measure of intra-limb coordination (Sparrow et al., 1987) that can improve understanding of how gross movement is organised, and for 
gait, therefore, how the translation of the CM is controlled. Intra-limb coordination analyses have been applied to constant velocity locomotive task such as walking (Chang et al., 2008), running (Hamill et al., 1999; Floría et al., 2019), and maximal velocity sprinting (Gittoes and Wilson, 2010). Vector coding methods (Sparrow et al., 1987; Chang et al., 2008; Needham et al., 2014) output a coupling angle, which can be easily related back to angular motion, providing an intuitive applied method for assessing movement coordination. To the authors' knowledge, coordination analyses have not yet been applied to the block and initial acceleration phases of a maximal sprint in an elite population. Given the additional task constraint of the high hurdle, inter-segment coordination analyses will afford greater insight into technique differences between elite sprint and hurdle athletes.

The purpose of this study was therefore to address the gaps in the research literature in an exceptional way, based on detailed biomechanical data collected from the finals of the 2018 IAAF World Indoor Championships. This is the first time in the biomechanics research literature that such data have been captured live, enabling a novel approach to examining an important aspect of sprint acceleration performance. The first aim of the study was to quantify and explain the start and initial acceleration technique of the world's best male sprinters and hurdlers in situ in an elite competition environment. Secondly, based on a comparison of the sprinters and hurdlers, the aim was to elucidate the mechanisms by which the athletes translate their CM during the start and initial acceleration phases, given the different task constraints placed on the athletes by the two events. Findings from this study will contribute new conceptual understanding of the mechanisms that underpin start and initial acceleration performance, for scientists, coaches and athletes.

\section{MATERIALS AND METHODS}

\section{Participants}

Data were collected as part of the Birmingham 2018 IAAF World Indoor Championships Biomechanics Research Project. The use of the data for this study was approved by the IAAF, who own and control the data, and locally through institutional research ethics procedures. The study was approved by the Leeds Beckett University Ethics sub-committee (School local approval by Research Ethics Coordinator). The patients/participants provided their written informed consent to participate in this study. The fifteen finalists of the men's $60 \mathrm{~m}$ and $60 \mathrm{~m}$ hurdles races (eight sprinters and seven hurdlers, because of a false start) were analysed in their respective races, on the evenings of $3 \mathrm{rd}$ and 4th March 2018 at Arena Birmingham, UK. All hurdlers took a seven-step approach to the first hurdle.

\section{Data Collection}

Four Sony PXW-FS7 cameras operating at $150 \mathrm{~Hz}$ (shutter speed: 1/1250 s; ISO: 2000-4000; FHD: $1920 \times 1080$ pixels) were used to capture motion of athletes during block and initial acceleration phases (see Figure 1). A calibration procedure was conducted before and after each race. A rigid cuboid calibration frame measuring $3.044 \times 3.044 \times 3.044 \mathrm{~m}$ and comprising 24 control points was used. It was sequentially positioned multiple times over discrete predefined areas along and across the track to ensure an accurate definition of a volume covering the starting blocks and initial acceleration phase of the race, from $1 \mathrm{~m}$ behind the start line to $5 \mathrm{~m}$ beyond the start line. This approach produced a large number of non-coplanar control points per individual calibrated volume and facilitated the construction of a local coordinate system in each neighbouring pair of lanes, that was then combined into a global coordinate system, originating $1 \mathrm{~m}$ behind the left edge of lane 1.

\section{Data Processing}

The video files were imported into SIMI Motion (SIMI Motion version 9.2.2, Simi Reality Motion Systems GmbH, Germany) and were manually digitised by a single experienced operator to obtain kinematic data. An event synchronisation technique (synchronisation of four critical instants) was applied through SIMI Motion to synchronise the two-dimensional coordinates from each camera involved in the recording. The digitising was carried out in two parts: a whole body analysis of specific discrete key events, and a continuous analysis of the trunk and rear leg throughout the start and initial acceleration phase. Firstly, a 17 point whole body model was digitised at the following key events; first visible movement from the set position (FM), rear foot block exit (RFBE), front foot block exit (FFBE), and touchdown and take-off events up to the touchdown of ground contact four $\left(\mathrm{GC1}_{\mathrm{TD}}, \mathrm{GCl}_{\mathrm{TO}}\right.$ etc... see Table 1). From block exit onwards, these events were defined as the last frame where the foot was visibly on the block or track, and the subsequent first frame where the foot was visibly on the track, respectively. The 17 digitised points were the centre of the head, and bilaterally shoulder, elbow, wrist, metacarpo-phalangeal, hip, knee, ankle, and metatarso-phalangeal (MTP) joint centres in accordance with de Leva (1996).

Secondly, the shoulder, hip, knee, ankle, and MTP joints on the side of the rear leg in the blocks were digitised continuously in every frame from the onset of movement in the blocks (FM) to the third take-off after block exit (GC3 $\left.{ }_{\mathrm{TO}}\right)$. Each video file was digitised frame by frame and upon completion, adjustments were made as necessary using the points over frame method (Bahamonde and Stevens, 2006). The Direct Linear Transformation algorithm (Abdel-Aziz and Karara, 1971) was used to reconstruct the three-dimensional coordinates from individual camera's $\mathrm{x}$ and $\mathrm{y}$ image coordinates. For all subsequent analysis, three-dimensional coordinates were projected onto a two-dimensional sagittal plane using only antero-posterior and vertical coordinates. Reliability of the digitising process was estimated by repeating the process for specific variables for eight randomly selected athletes with an intervening period of $48 \mathrm{~h}$. The results showed minimal total errors (CM vertical coordinate in the set position: $\mathrm{RMSD}=0.0056 \mathrm{~m}, \mathrm{ICC}=0.999$; knee angle at third touchdown: $\left.\mathrm{RMSD}=1.0^{\circ}, \mathrm{ICC}=0.994\right)$ and therefore confirmed the high reliability of the digitising process.

All further data processing was done in Matlab (v2019a, Natick, MA). de Leva (1996) body segment parameter model was used to obtain data for the whole body CM and for key body segments of interest. A recursive second-order, low-pass 


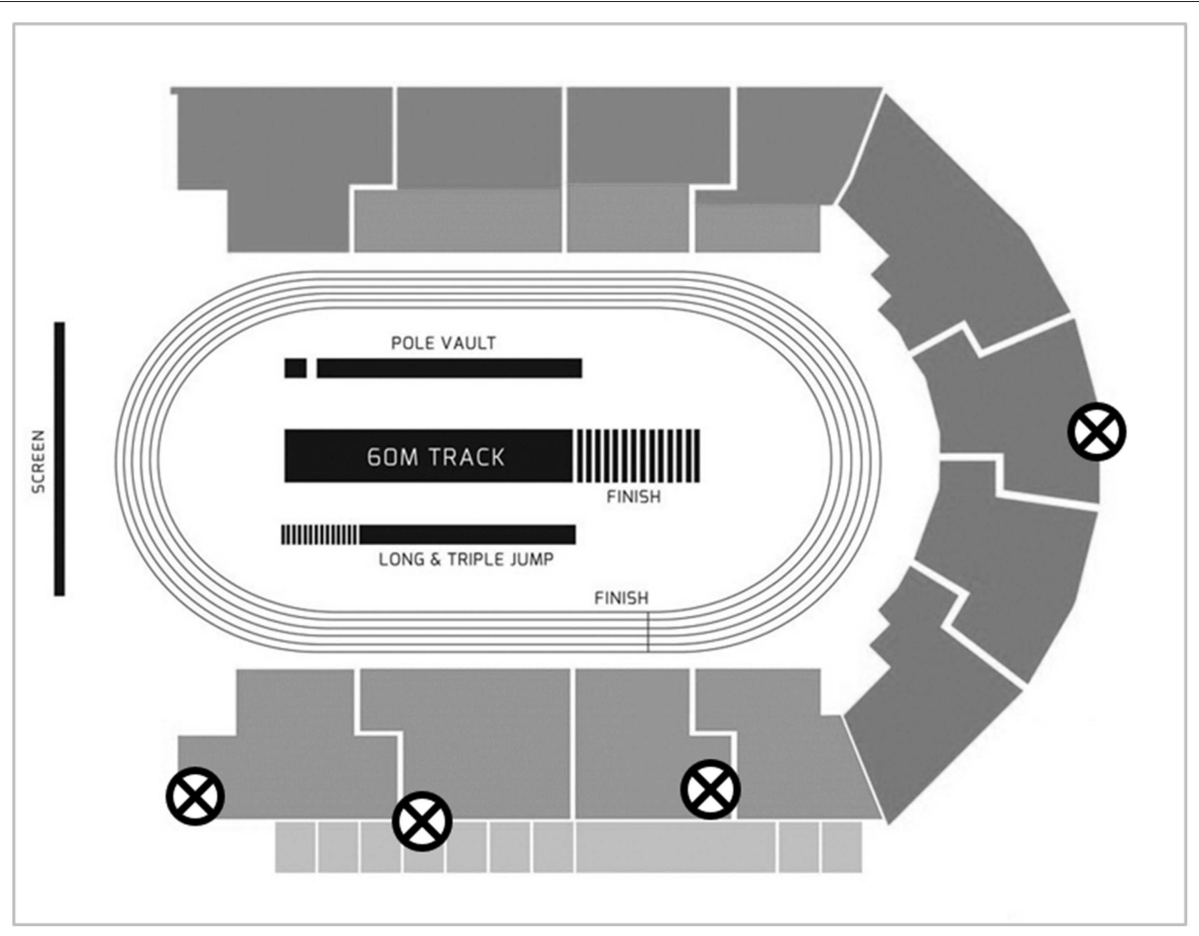

FIGURE 1 | Camera positions for data capture. The four cameras are each marked with an $\otimes$.

Butterworth digital filter (zero phase-lag) was employed to filter the raw coordinate data for the five joint centres digitised continuously throughout the movement. The cut-off frequencies were calculated (mean $13.3 \mathrm{~Hz}$, range $10.0-15.5 \mathrm{~Hz}$ ) using residual analysis (Winter, 2009).

For the whole-body analysis at key events, all linear displacement variables (horizontally and vertically for $\mathrm{CM}$ and joint centres) were scaled according to the stature of the athletes measured from the digitised data, to account for any differences in height between the two groups. Based on the approach of Ciacci et al. (2017), the sum of the length of shank, thigh and trunk segments was calculated for each athlete for all frames. All linear displacements were divided by this individual scaling factor (mean: $1.359 \mathrm{~m}$ for sprinters and $1.456 \mathrm{~m}$ for hurdlers), and are therefore presented as dimensionless values. Block spacings were calculated based on the coordinates of the two MTP joint centres in the set position, and were not scaled to stature. Segment angles were defined in an anticlockwise direction relative to the global forward horizontal, and joint angles were defined with extension as positive (see Figure 2).

For the continuous data analysis of the shoulder, hip, knee, ankle and MTP joints on the side of the rear leg in the blocks, all relevant data (joint centre coordinates and segment angles) were time normalised based on key events relevant to the rear foot in the blocks. Those six events were FM, RFBE, $\mathrm{GCl}_{\mathrm{TD}}, \mathrm{GCl}_{\mathrm{TO}}$, $\mathrm{GC}_{\mathrm{TD}}$, and GC3 $3_{\mathrm{TO}}$. Between each successive event the data were time-normalised to 101 data points using a cubic spline. This gave a total of 501 data points from FM to GC3 ${ }_{\mathrm{TO}}$. The mean value of the time of FFBE for each group was calculated as a percentage between the RFBE and $\mathrm{GC1} 1_{\mathrm{TD}}$ events.
TABLE 1 | Abbreviations used in the study.

\begin{tabular}{ll}
\hline Abbreviation & Meaning \\
\hline $\mathrm{CM}$ & Centre of mass \\
FM & First movement \\
RFBE & Rear foot block exit \\
FFBE & Front foot block exit \\
GC1, GC2, GC3 & Ground contact one, two and three \\
GC1TD, etc... & Ground contact one touchdown, etc... \\
GC1 1 TO, etc... & Ground contact one take-off, etc... \\
MTP & Metatarso-phalangeal \\
SD & Standard deviation \\
CA & Coupling angle \\
CADIF & Coupling angle difference \\
\hline
\end{tabular}

All between group comparisons were made using group means and standard deviations (SD), with unpaired samples 95\% confidence intervals calculated, based on the differences between the two groups (Altman and Gardner, 2000). All differences were calculated as sprinters minus hurdlers. Group responses were considered different where the $95 \%$ confidence intervals did not cross zero (Altman and Gardner, 2000), for both discrete and continuous data. Analysis of discrete data was supplemented with effect size (Cohen's $d$ ) calculations, with mean and pooled SD calculated according to Altman and Gardner (2000). The effect size magnitude was classified according to the scale proposed by Hopkins et al. (2009). Positive effect sizes represented comparisons where sprinters had a larger value than hurdlers, 


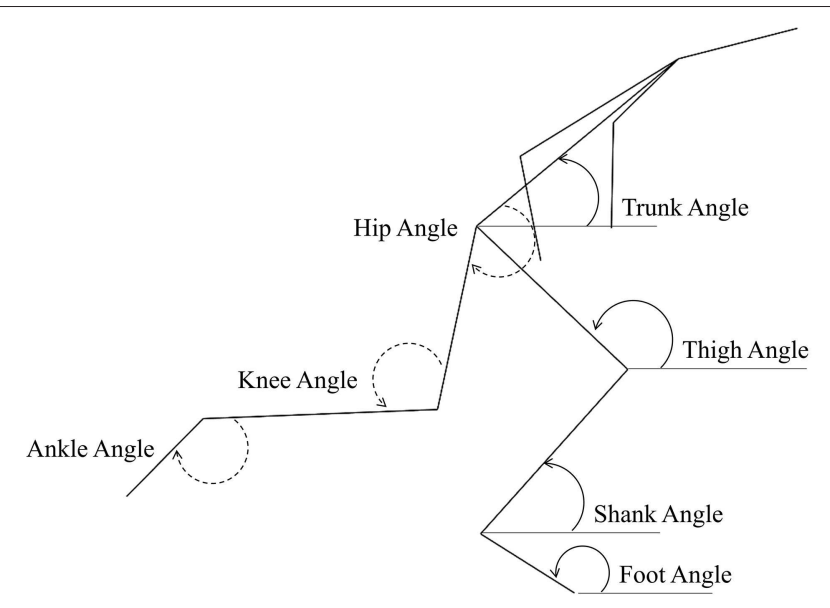

FIGURE 2 | Segment and joint angle definitions used in the study. Segment angles are represented on the ground leg (right, solid line), and joint angles are represented on the swing (left) leg.

and negative effect sizes represented comparisons where hurdlers had a larger value than sprinters. Data are presented in the results as (difference in means, 95\% confidence interval, effect size classification), according to Altman and Gardner (2000).

\section{Intra-Limb Coordination Analysis}

Vector coding techniques (Chang et al., 2008; Needham et al., 2014) were applied to individual and ensemble group mean angle-angle plots for the trunk-thigh, trunk-shank and thighshank couples, to obtain the coupling angle (CA) at each instance of the normalised time cycle between FM and $\mathrm{GC}^{\mathrm{TO}}$. Specifically, CA was calculated as the orientation of the vector between two adjacent points on the angle-angle plot, relative to the right horizontal and expressed between 0 and $360^{\circ}$ (Figure 3A). CA data were then "binned" into one of eight distinct coordination patterns (Chang et al., 2008) based on each segment's relative motion (Figure 3B), with each coordination pattern assigned a specific colour. The colour assignment could then be used to profile coordination across the normalised time cycle to aid visual identification of coordination differences within and between each group. To quantify overall differences in coordination between the sprint and hurdle groups, a coupling angle difference $\left(\mathrm{CA}_{\mathrm{DIF}}\right)$ was calculated, by computing a "difference score" in coordination pattern (bin), ranging from 0 (same bin) to 4 (opposite bin) at each instance across the normalised time cycle (Figure 3B). The sum of each difference score was then expressed as a percentage of the maximum possible value, with a lower $\mathrm{CA}_{\mathrm{DIF}}$ representing closer similarity in coordination patterns.

\section{RESULTS}

\section{Discrete Analysis at Key Events}

Visual inspection of whole body positions adopted by the two groups at key events (Figure 4) showed differences in block spacings and thigh angles at first movement, but otherwise
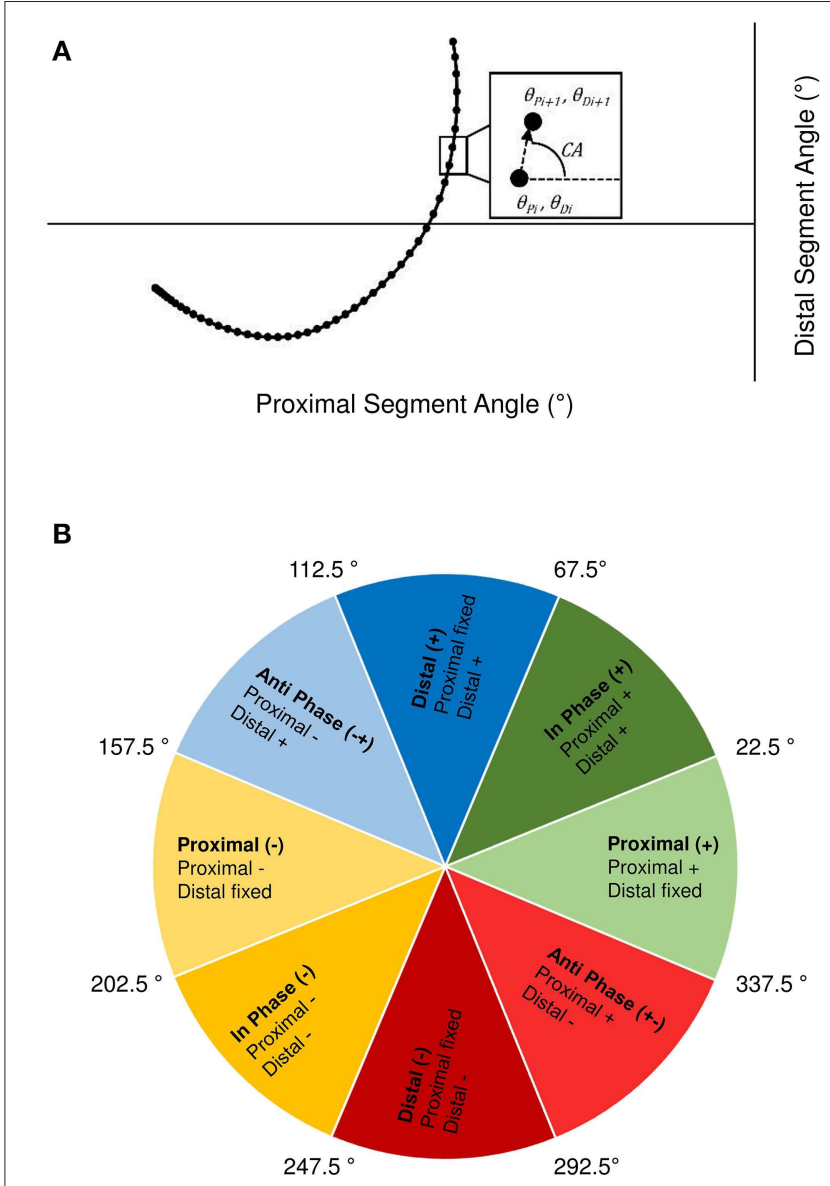

FIGURE 3 | Definition of the coupling angle (CA) from segmental angle-angle plots (A) and classification of coordination patterns into distinct "bins" based on the relative motion of the proximal and distal segment (B). Anticlockwise and clockwise segment rotation are defined as positive $(+)$ and negative $(-)$, respectively.

similar patterns were observed at block exit events. At subsequent touchdown and take-off events sprinters' trunk and shank segments were generally more forward orientated than hurdlers'. Additional temporal analysis (Table 2) showed that although reaction time was identical, hurdlers spent longer in both doubleand single-leg push (double-leg difference $-0.023 \mathrm{~s},-0.043$ to -0.003 , large effect; single-leg difference $-0.031 \mathrm{~s},-0.050$ to -0.012 , large effect) and the total block phase (difference $-0.054 \mathrm{~s},-0.080$ to -0.028 , very large effect). With the exception of contact time for ground contacts two and four, all contact and flight times were longer in the hurdlers (medium to very large effects). Overall, the total time to the fourth take-off was greater in the hurdlers than the sprinters (difference $-0.228 \mathrm{~s},-0.268$ to -0.188 , extremely large effect). The hurdlers' blocks were set up with both feet nearer to the start line (front foot difference $0.24 \mathrm{~m}$, 0.16 to 0.33 , very large effect; rear foot difference $0.13 \mathrm{~m}, 0.03$ to 0.24 , large effect), and a greater spacing between the two blocks (difference $-0.10 \mathrm{~m},-0.17$ to -0.04 , large effect).

The clearest differences in translation of the CM occurred during the block phase, particularly after rear foot block exit, 


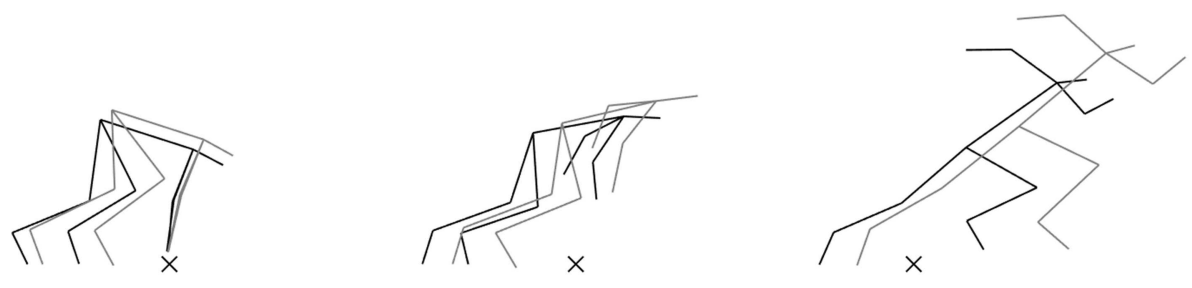

\section{GC1}

\section{${ }^{\mathrm{GC}} 1_{\text {Tо }}$}
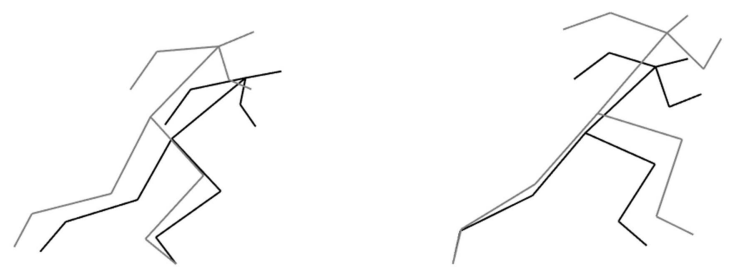

GC3 ${ }_{\text {TD }}$

GC3 ${ }_{\text {TO }}$
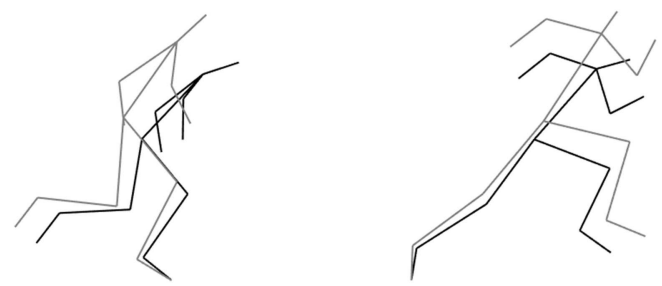

FIGURE 4 | Stick figures showing absolute mean segmental orientations of sprinters (black) and hurdlers (grey) at key events related to the rear leg in the blocks. Block phase events are aligned according to the mean locations of the metacarpal-phalangeal joint centres, with the start line marked ( $\times$ ). Touchdown and take-off events are aligned to the mean locations of the MTP joint of the ground contact leg.

and during the flight phases succeeding each post-block foot contact. Hurdlers displaced their CM vertically and horizontally more than sprinters between RFBE and FFBE (vertical difference $-0.037,-0.057$ to -0.018 , very large effect; horizontal difference $-0.075,-0.111$ to -0.038 , very large effect, Figures $5 \mathbf{A}, \mathbf{B}$ ). Differences in CM vertical displacement changes between RFBE and FFBE were mirrored in changes at the shoulder (vertical difference $-0.039,-0.068$ to -0.011 , large effect), hip (vertical difference $-0.051,-0.080$ to -0.022 , large effect) and knee (vertical difference $-0.049,-0.082$ to -0.016 , large effect) during the same phase, which were all greater in hurdlers than sprinters (Figures 6A-C).

Whilst there was a clear overlap in confidence intervals for change of CM vertical displacement between FM and RFBE (difference $-0.011,-0.026$ to 0.004 , moderate effect, Figure 5A), the range of responses was clearly greater in hurdlers than sprinters, indicating more variability within the hurdler group (SD hurdlers 0.019 , SD sprinters 0.005 ). This was reflected in more variability in the hurdlers in the vertical displacement of both hip (SD hurdlers 0.043 , SD sprinters 0.031 ) and knee joint centres (SD hurdlers 0.035, SD sprinters 0.014), but less variability in the raising of the shoulder (SD hurdlers $0.014, \mathrm{SD}$ sprinters 0.032). At each of those joints there was a clear overlap in the confidence intervals for the magnitude of the change in $\mathrm{CM}$ vertical displacement (small effect, shoulder and knee; no difference, hip; Figures 6A-C).

During initial acceleration hurdlers produced greater horizontal CM displacement than sprinters in each of the second 
TABLE 2 | Durations of key phases from the starting gun to the end of the fourth foot contact, and block spacing distances, for sprinters and hurdlers (Mean \pm SD).

\begin{tabular}{|c|c|c|c|c|c|}
\hline Variable & Sprinters & Hurdlers & Difference & $95 \%$ Confidence interval & Effect size $(d)$ \\
\hline Reaction time [s] & $0.155 \pm 0.010$ & $0.155 \pm 0.018$ & $<0.001$ & -0.016 to 0.016 & $0.01^{N D}$ \\
\hline Double-leg push time [s] & $0.194 \pm 0.018$ & $0.217 \pm 0.018$ & -0.023 & -0.043 to $-0.003^{\star}$ & $-1.29^{L}$ \\
\hline Single-leg push time [s] & $0.148 \pm 0.018$ & $0.179 \pm 0.016$ & -0.031 & -0.050 to $-0.012^{\star}$ & $-1.81^{\mathrm{L}}$ \\
\hline Total block time [s] & $0.497 \pm 0.027$ & $0.551 \pm 0.018$ & -0.054 & -0.080 to $-0.028^{\star}$ & $-2.32^{\mathrm{VL}}$ \\
\hline Flight time $1[\mathrm{~s}]$ & $0.044 \pm 0.012$ & $0.077 \pm 0.016$ & -0.033 & -0.048 to $-0.018^{*}$ & $-2.39^{V L}$ \\
\hline Contact time 1 [s] & $0.175 \pm 0.014$ & $0.210 \pm 0.034$ & -0.035 & -0.064 to $-0.007^{\star}$ & $-1.40^{\mathrm{L}}$ \\
\hline Flight time 2 [s] & $0.058 \pm 0.012$ & $0.083 \pm 0.013$ & -0.025 & -0.040 to $-0.011^{*}$ & $-1.99^{L}$ \\
\hline Contact time 2 [s] & $0.171 \pm 0.014$ & $0.165 \pm 0.016$ & 0.006 & -0.011 to 0.023 & $0.41^{\mathrm{S}}$ \\
\hline Flight time 3 [s] & $0.063 \pm 0.012$ & $0.099 \pm 0.012$ & -0.037 & -0.050 to $-0.023^{\star}$ & $-2.96^{\mathrm{VL}}$ \\
\hline Contact time 3 [s] & $0.138 \pm 0.011$ & $0.154 \pm 0.018$ & -0.017 & -0.033 to $-0.001^{*}$ & $-1.16^{\mathrm{M}}$ \\
\hline Flight time 4 [s] & $0.072 \pm 0.010$ & $0.099 \pm 0.010$ & -0.027 & -0.038 to $-0.016^{\star}$ & $-2.78^{\mathrm{VL}}$ \\
\hline Contact time 4 [s] & $0.136 \pm 0.016$ & $0.142 \pm 0.008$ & -0.006 & -0.020 to 0.008 & $-0.48^{S}$ \\
\hline Total time to end of fourth contact [s] & $1.352 \pm 0.040$ & $1.580 \pm 0.029$ & -0.228 & -0.268 to $-0.188^{\star}$ & $-6.40^{\mathrm{EL}}$ \\
\hline Front foot toe distance from start line in blocks [m] & $0.56 \pm 0.05$ & $0.33 \pm 0.08$ & 0.24 & 0.16 to $0.33^{\star}$ & $3.36^{\mathrm{VL}}$ \\
\hline Back foot toe distance from start line in blocks [m] & $0.84 \pm 0.05$ & $0.71 \pm 0.12$ & 0.13 & 0.03 to $0.24^{\star}$ & $1.40^{\mathrm{L}}$ \\
\hline Block spacing [m] & $0.28 \pm 0.03$ & $0.38 \pm 0.08$ & -0.10 & -0.17 to $-0.04^{\star}$ & $-1.70^{\mathrm{L}}$ \\
\hline
\end{tabular}

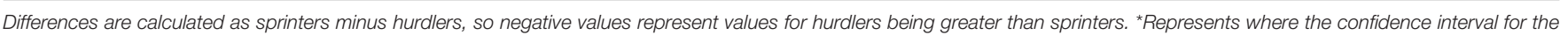

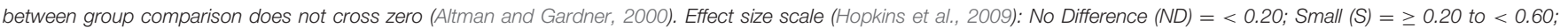
Moderate $(M)=\geq 0.60<1.20$; Large $(L)=\geq 1.20$ to $<2.00$; Very Large $(V L)=\geq 2.00$ to $<4.00$; Extremely Large $(E L)=\geq 4.00$.

to fourth flight phases $\left(\mathrm{GC}_{\mathrm{TO}}-\mathrm{GC} 2_{\mathrm{TD}}\right.$ difference -0.110 , -0.169 to -0.052 , very large effect; $\mathrm{GC} 2 \mathrm{TO}-\mathrm{GC} 3 \mathrm{TD}$ difference $-0.097,-0.157$ to -0.037 , large effect; $\mathrm{GC}{ }_{\mathrm{TO}}-\mathrm{GC} 4 \mathrm{TD}$ difference $-0.181,-0.247$ to -0.114 , very large effect; Figure 5B). These group-level differences in change in CM horizontal displacement were reflected by the shoulder, hip, knee, and ankle in each of the second, third and fourth flight phases (large to very large effects, Figure 7).

\section{Continuous and Angular Analysis}

During the first swing phase (at 160\% normalised time from FM to $\mathrm{GC}_{\mathrm{TO}}$ i.e., at $60 \%$ time from $\mathrm{RFBE}$ to $\mathrm{GC1}_{\mathrm{TD}}$ ), the hurdlers had raised their shoulders to a greater extent, when accounting for stature, and maintained this through the remainder of the initial acceleration phase (Figure 8B). There were no clear differences in joint and segment angles of the rear leg in the set position, but moderate effect sizes for a more flexed hip and vertical thigh in the hurdlers (Figure 9, Table 3). The front leg hip angle was more flexed in the hurdlers in the set position (difference $10^{\circ}, 2$ to 18 , large effect), with no clear differences but a moderate effect size for hurdlers' thigh being more horizontal and shank being more vertical (Figure 9, Table 3).

After FM, hurdlers briefly had a more vertically orientated thigh segment than sprinters during the double-leg push phase (from 47 to $71 \%$ time) and around the transition from doubleto single-leg push (93-124\% time, Figure 9D). During the initial acceleration phase, hurdlers had more vertically orientated trunk and shank segments, as well as a more horizontally orientated foot segment late in the first swing and early into the first ground contact phase (trunk, 161-230\% and 239-279\%, Figure 9B; shank 156-268\%, Figure 9F; foot 153-280\%, Figure 9H). These differences at the trunk, shank, and foot occurred again late in the second swing phase and into the third ground contact (trunk, 286-500\%, Figure 9B; shank 348-440\%, Figure 9F; foot 349-479\%, Figure 9H), and continued thereafter at the trunk, with a more upright posture maintained throughout the initial acceleration phase. The thigh segment was briefly more upright in the hurdlers late in the second swing phase (from 361 to $379 \%$ time, Figure 9D). The only clear difference in the ranges of motion of joints or segments between each of the key events investigated, was at the foot during the first ground contact (difference $15^{\circ}, 1$ to 30 , moderate effect, Table 3 ). There were, however, also moderate effect sizes for range of motion of the trunk segment between FM and both RFBE and $\mathrm{GC1}_{\mathrm{TD}}$, with hurdlers showing greater values (FM-RFBE difference $-6^{\circ},-15$ to 4 , moderate effect; $\mathrm{FM}-\mathrm{GC} 1_{\mathrm{TD}}$ difference $-8^{\circ},-17$ to 1 , moderate effect).

\section{Intra-Limb Segmental Coordination Trunk-Thigh}

Coordination of the trunk-thigh segments was similar between groups, with $\mathrm{CA}_{\mathrm{DIF}}$ magnitudes of 7\% during the double-leg push phase and 1-3\% after RFBE (Figure 10). The greater difference during the double-leg push was mainly attributed to the onset of movement. From FM, sprinters exhibited an earlier transition and longer duration of distal (-) coordination (dark red), whereas hurdlers spent a greater duration of this initial movement in coordination patterns dominated by anticlockwise trunk rotation (anti phase +- , light red; in-phase + , dark green, Figure 10). During $\mathrm{GC}_{1}$ and $\mathrm{GC}_{3}$ both groups exhibited a dominance of distal ( - ) coordination as the thigh rotated clockwise and trunk angle remained relatively fixed (Figures 10, 11).

\section{Trunk-Shank}

The greatest inter-group and inter-individual differences in trunk-shank coordination were again attributed to the onset 


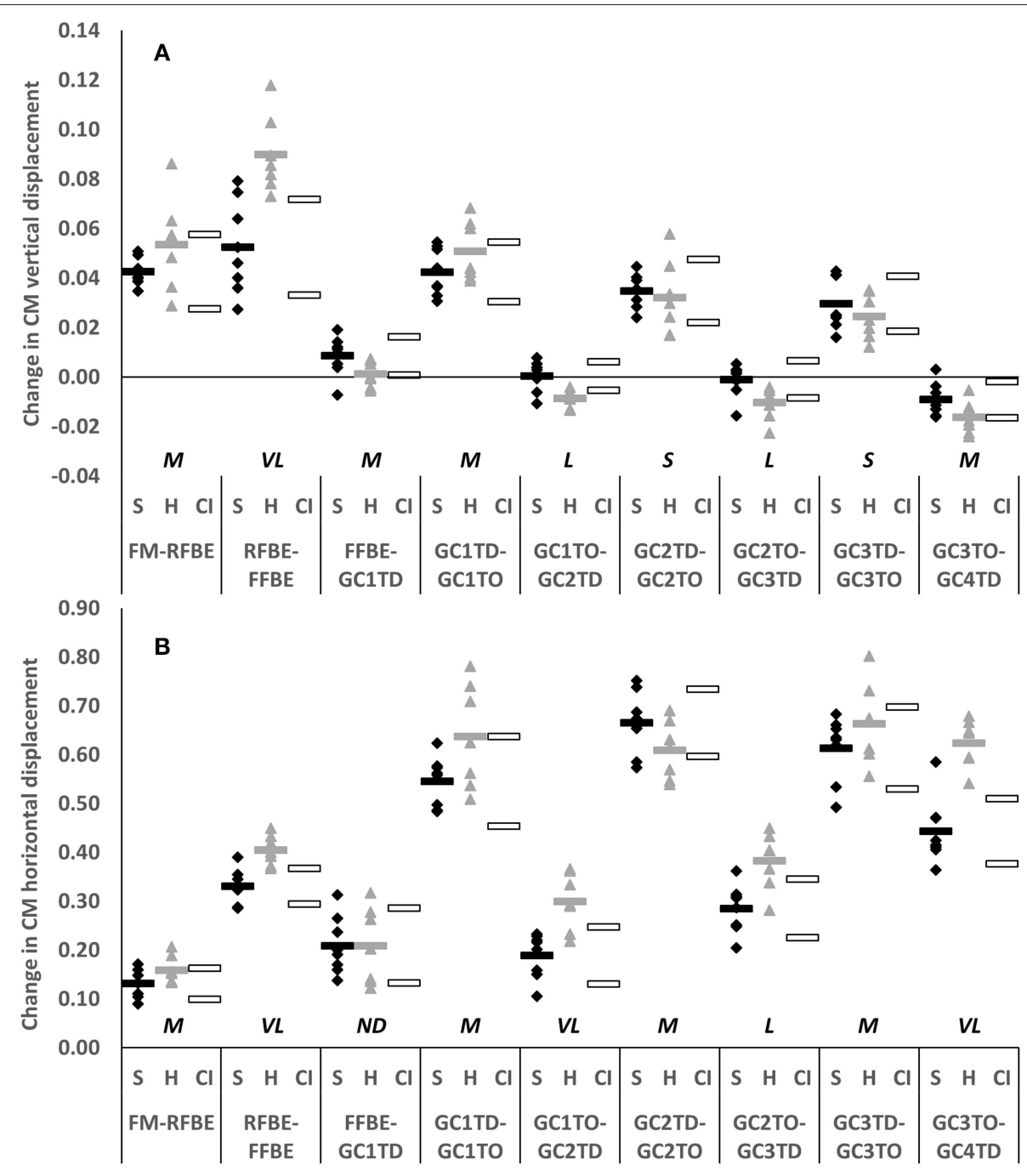

FIGURE 5 | Change in vertical (A) and horizontal displacement (B) of whole body CM of sprinters (black diamonds) and hurdlers (grey triangles) between successive key events, scaled to stature. Group means are represented by shaded rectangles, and 95\% confidence intervals with white rectangles. Values for hurdlers are different from sprinters where the hurdlers mean falls outside the 95\% confidence intervals [i.e., where the confidence interval for the between group comparison does not cross zero (Altman and Gardner, 2000)]. Effect size classifications are represented above x-axis labels (Hopkins et al., 2009): No Difference (ND) = < 0.20; Small $(S)=\geq 0.20$ to $<0.60 ;$ Moderate $(M)=\geq 0.60<1.20$; Large $(L)=\geq 1.20$ to $<2.00$, Very Large $(V L)=\geq 2.00$ to $<4.00 ;$ Extremely Large $(E L)=\geq 4.00$.

of movement (Figures 10, 11). Of all phases during initial acceleration $\mathrm{CA}_{\mathrm{DIF}}$ was higher during the double-leg push phase (10\%), first swing (12\%) and $\mathrm{GC}_{1}$ (14\%), although coordination patterns between the two groups were often within one bin (Figure 10). An earlier onset of anticlockwise shank rotation after RFBE in the hurdle group resulted in an earlier transition away from anti phase $(+-)$ coordination, through to in-phase $(+)$ and eventually distal $(+)$ coordination once the trunk ceased anticlockwise rotation (Figure 10). During $\mathrm{GC}_{1}$, group differences in coordination arose around mid-stance, with sprinters and hurdlers showing proximal $(-)$ and in phase $(-)$ patterns, respectively. Individual analysis (Figure 11) again highlighted the overall consistency within and between groups with all athletes adopting the same main patterns of coordination after movement onset. Individual differences manifested themselves through temporal shifts between coordination patterns and the time spent in each, as opposed to any clear differences in the major coordination patterns adopted.

\section{Thigh-Shank}

At a group level, the largest $\mathrm{CA}_{\mathrm{DIF}}$ was apparent during $\mathrm{GC}_{3}$ $(18 \%)$ as patterns of proximal (-) and anti phase (-+) dominated for the sprint and hurdle groups, respectively, although absolute differences in the coupling angle were small (Figure 10). Once more, both group and individual analyses highlighted the overall consistency in coordination patterns, with temporal differences in the transition between major coordination patterns dictating inter-group and inter-individual differences (Figures 10, 11). 

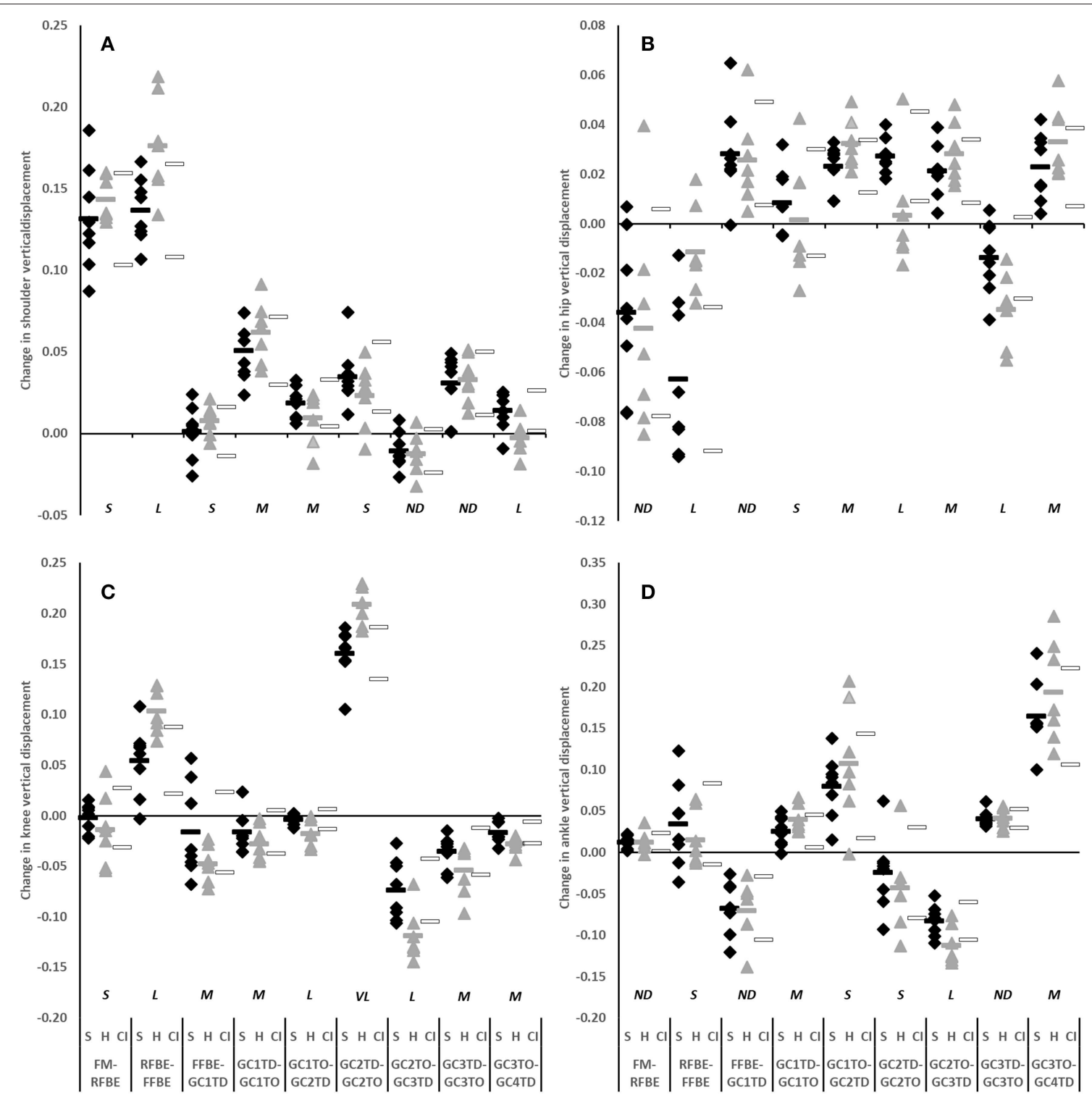

FIGURE 6 | Change in vertical displacement of shoulder (A), hip (B), knee (C), and ankle (D) of sprinters (black diamonds), and hurdlers (grey triangles) between successive key events, scaled to stature. Group means are represented by shaded rectangles, and $95 \%$ confidence intervals with white rectangles. Values for hurdlers are different from sprinters where the hurdlers mean falls outside the $95 \%$ confidence intervals [i.e., where the confidence interval for the between group comparison does not cross zero (Altman and Gardner, 2000)]. Effect size classifications are represented above $x$-axis labels (Hopkins et al., 2009): No Difference (ND) $=<0.20$; Small $(S)=\geq 0.20$ to $<0.60$; Moderate $(M)=\geq 0.60<1.20$; Large $(L)=\geq 1.20$ to $<2.00$, Very Large $(V L)=\geq 2.00$ to $<4.00$; Extremely Large $(E L)=\geq 4.00$.

\section{DISCUSSION}

The first aim of this study was to quantify and explain the start and initial acceleration technique of the world's best male sprinters and hurdlers in situ in an elite competition environment. This is the first time in the biomechanics research literature that such data have been captured live, in this case from the finals of the 2018 IAAF World Indoor Championships, enabling a novel approach to examining an important aspect of sprint acceleration performance. Secondly, based on a comparison of the sprinters and hurdlers, the aim was to elucidate the mechanisms by which the athletes translate their $\mathrm{CM}$ during the start and initial acceleration phases. Despite the different task constraints placed on the athletes by the two events, there were many similarities between the kinematic and intersegment coordination profiles of the world-class sprinters and hurdlers investigated in the current study.

Overall, the similarity in coordination patterns found in this study (Figures 10, 11) is an important and novel finding that will be particularly useful for scientists, coaches and 

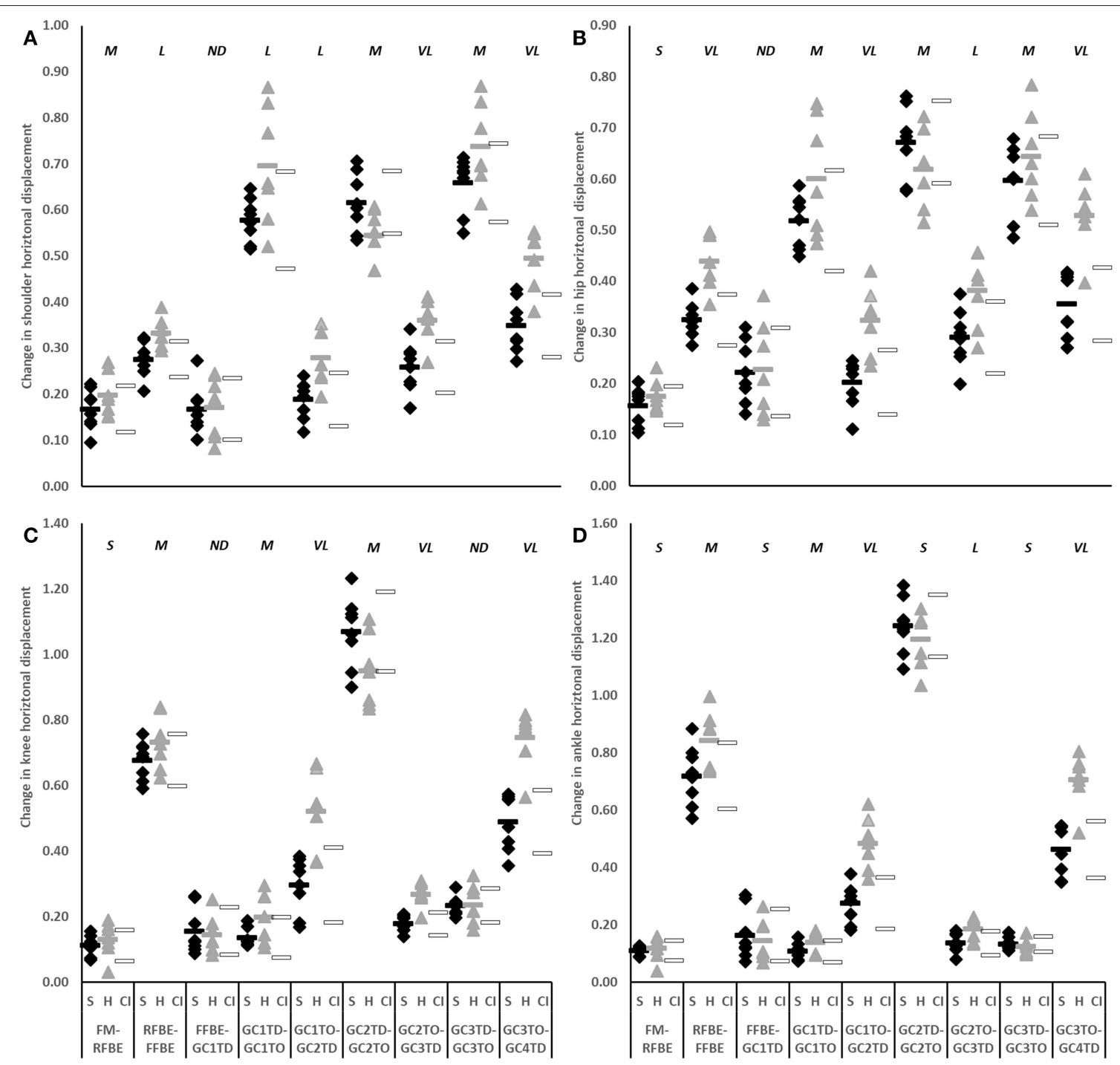

FIGURE 7 | Change in horizontal displacement of shoulder (A), hip (B), knee (C), and ankle (D) of sprinters (black diamonds), and hurdlers (grey triangles) between successive key events, scaled to stature. Group means are represented by shaded rectangles, and $95 \%$ confidence intervals with white rectangles. Values for hurdlers are different from sprinters where the hurdlers mean falls outside the $95 \%$ confidence intervals [i.e., where the confidence interval for the between group comparison does not cross zero (Altman and Gardner, 2000)]. Effect size classifications are represented above x-axis labels (Hopkins et al., 2009): No Difference (ND) $=<0.20$; Small $(S)=\geq 0.20$ to $<0.60$; Moderate $(M)=\geq 0.60<1.20$; Large $(L)=\geq 1.20$ to $<2.00$, Very Large $(V L)=\geq 2.00$ to $<4.00$; Extremely Large $(E L)=\geq 4.00$.

athletes. The world-class sprinters and hurdlers studied here organised their lower limb and trunk movement in a similar manner, and this contributes new conceptual understanding of the mechanisms that underpin start and initial acceleration performance. The differences in the raising of the CM are unlikely to be a result of differences in coordination through the start and initial acceleration phase, but result from small differences in the set position and a summation of small to moderate differences in extension range of motion throughout each push-off phase (Table 2). Those differences in the set position often come about as a strategic decision by coach and hurdler, to ensure that the athlete has less total distance to cover to reach the first hurdle (Mann and Murphy, 2018).

Following a near-identical reaction time in the sprinters and hurdlers, phase times were longer in hurdlers than sprinters in all phases up to take-off from the fourth contact, with the exception of the contact times when the front leg in the blocks was in contact with the track. These longer phase durations (Table 2), in addition to the hurdlers displacing their CM more horizontally during the single-leg push on the blocks and flight phases following the first post-block ground contact (Figure 5), might be a consequence of all hurdlers adopting a seven-step approach to the first hurdle. However, with no hurdlers electing 

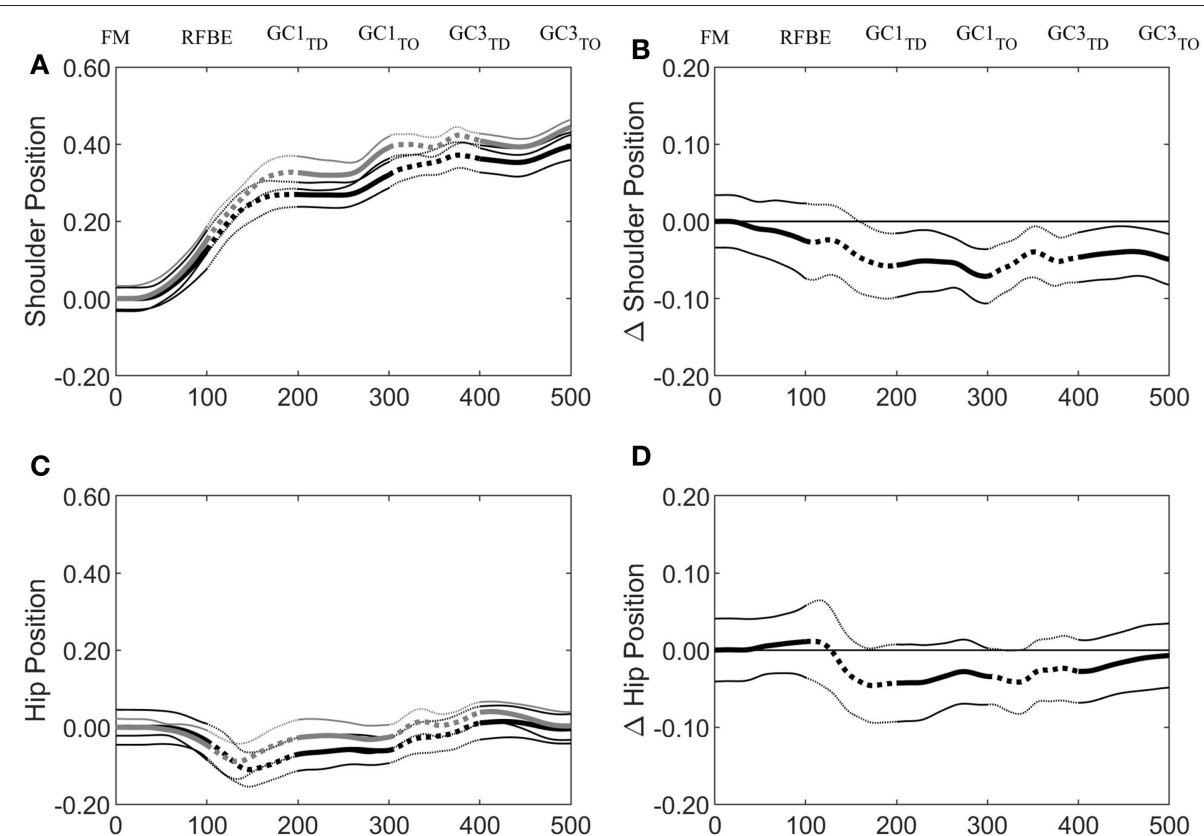

D

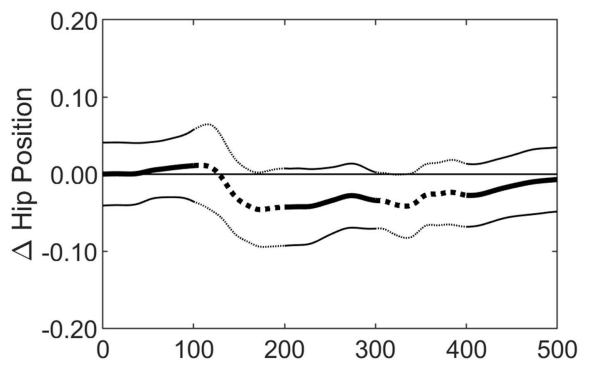

E

F
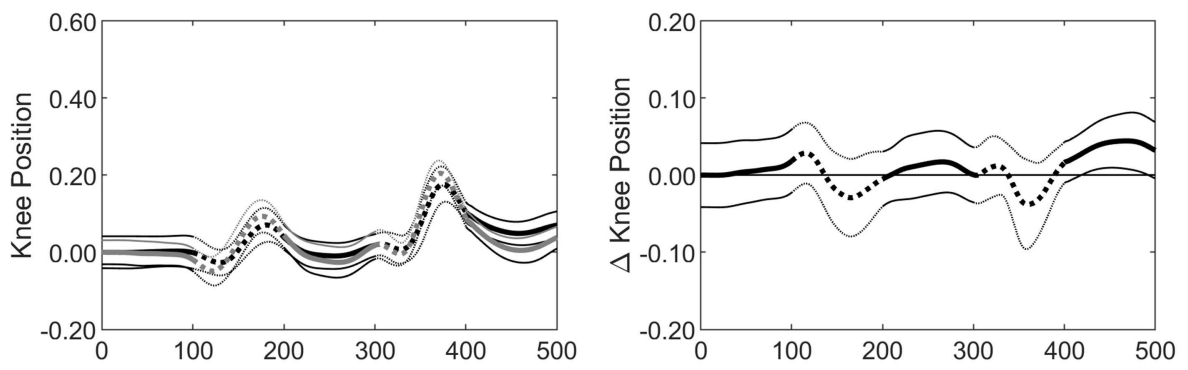

G

H
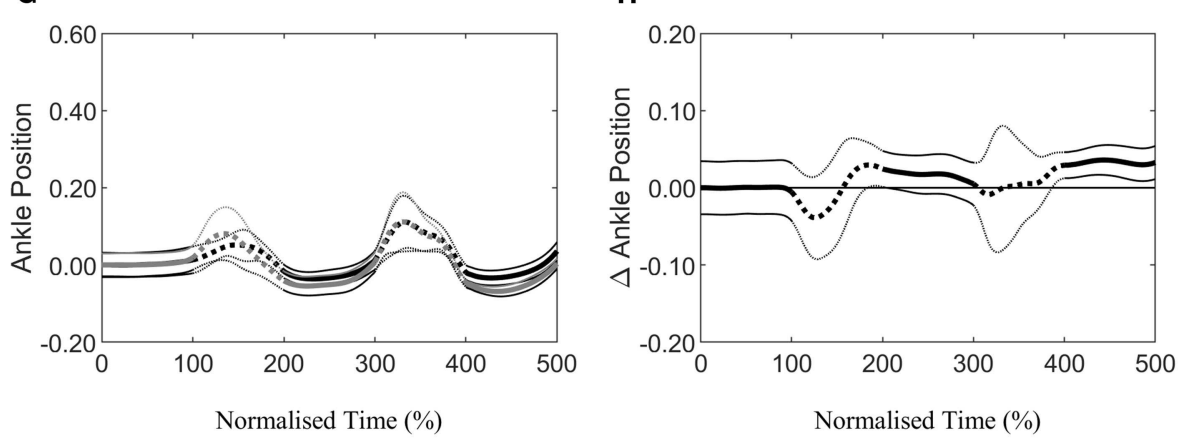

FIGURE 8 | Continuous vertical position relative to the set position (Mean \pm SD) of the shoulder (A), hip (C), knee (E), and ankle (G), scaled to individual stature for sprinters (black) and hurdlers (grey), and corresponding differences (B,D,F,H) between the sprinters, and hurdlers (thick line), and 95\% confidence interval (thin line). Positive differences indicate a greater value for sprinters, and negative differences a greater value for hurdlers. Sections where the confidence interval bands do not cross zero (x-axis) represent clear differences between groups. Solid lines represent the double-leg push phase in the blocks, and first and third ground contacts, whereas dashed lines represent the first and second swing phases of the rear leg, with key events related to the rear leg in the blocks marked above the figure.

to adopt an eight-step approach in this final, a direct comparison of the two strategies is not possible. Nonetheless, the sevenstep approach to the first hurdle demands steps in the initial acceleration phase on average to be lengthened, both spatially and temporally (Mann and Murphy, 2018), and that was clearly evident here in comparison to the sprinters. It was interesting to note that the contact times that showed no difference between hurdlers and sprinters were those that were taken with what would be the lead leg during subsequent hurdle clearances. It is beyond the scope of this study to investigate the differing roles of 

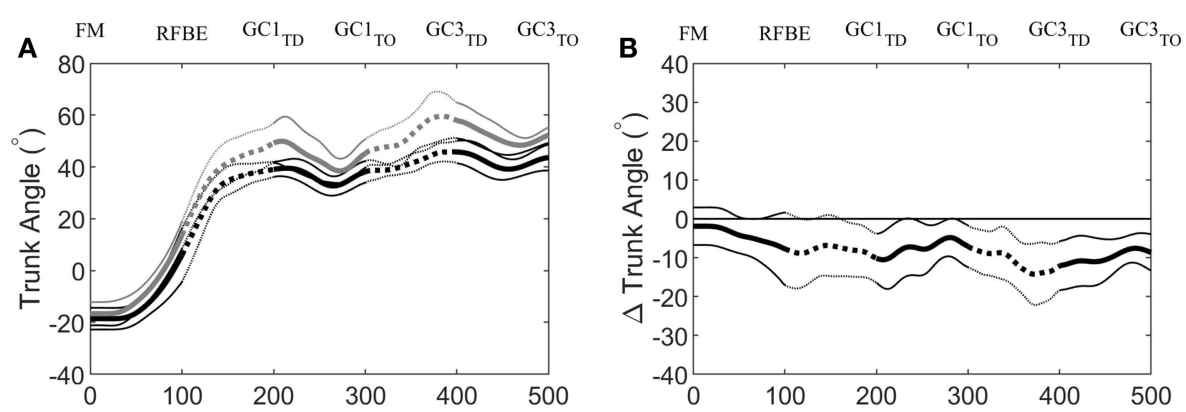

C

D
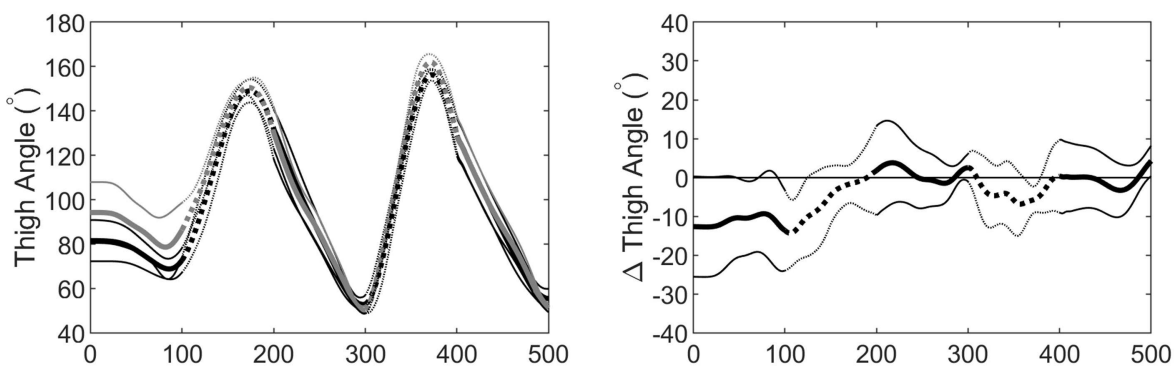

E

F
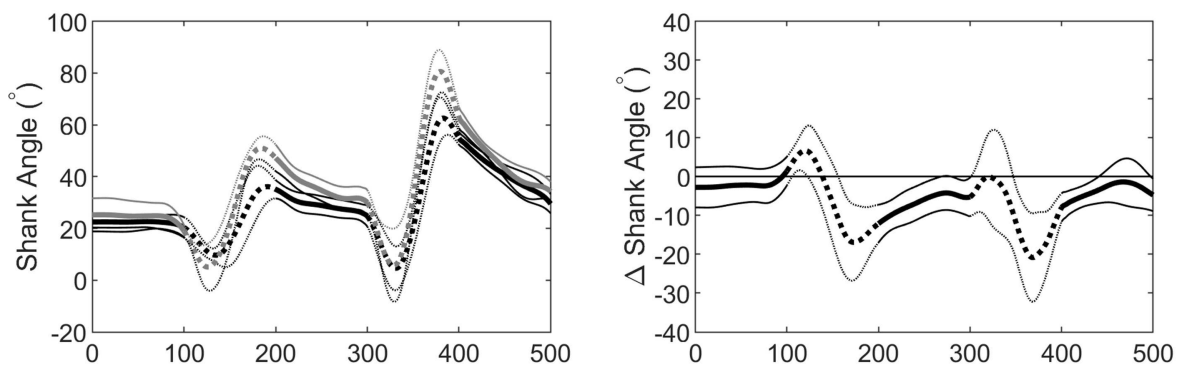

G

H
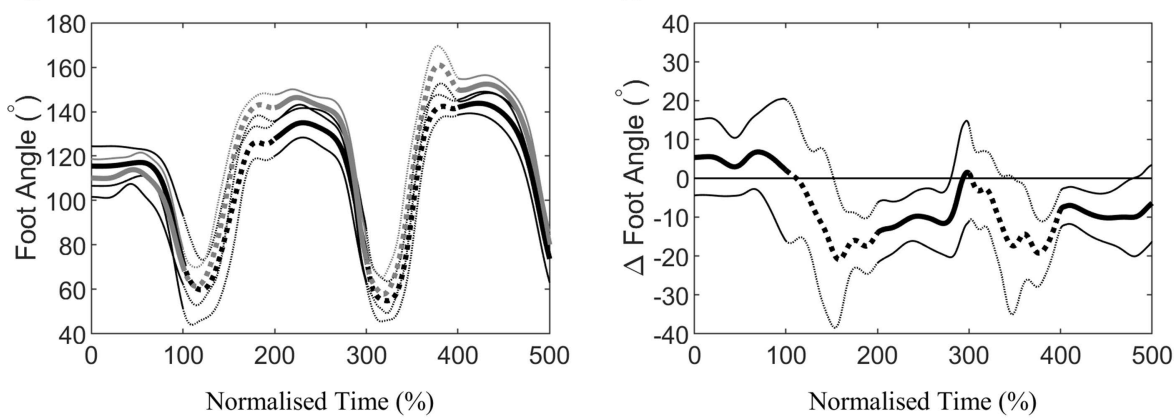

FIGURE 9 | Continuous segment angles (Mean \pm SD) of the trunk (A), thigh (C), shank (E), and foot (G), for sprinters (black) and hurdlers (grey), and corresponding differences (B,D,F,H) between the sprinters, and hurdlers (thick line), and 95\% confidence interval (thin line). Positive differences indicate a greater value for sprinters, and negative differences a greater value for hurdlers. Sections where the confidence interval bands do not cross zero ( $\mathrm{x}$-axis) represent clear differences between groups. Solid lines represent the double-leg push phase in the blocks, and first and, third ground contacts, whereas dashed lines represent the first and second swing phases of the rear leg, with key events related to the rear leg in the blocks marked above the figure. For definitions of segment angles (see Figure 2).

lead and trail legs further, but it is an interesting avenue for future research, especially given the asymmetrical and repetitive nature of the hurdle-unit gait cycle.

The hurdlers used a larger block spacing than the sprinters (difference $-0.10 \mathrm{~m},-0.17$ to -0.04 , large effect, Table 1).
According to block spacing classifications typically used, the hurdlers' mean spacing was medium, whilst the sprinters' was bunched (Slawinski et al., 2012). Despite the effects of relative block spacing being well-known (e.g., Henry, 1952; Slawinski et al., 2012), and supported in this study with greater spacings 
TABLE 3 | Joint and segment angles in the set position, and range of motion throughout initial acceleration for sprinters and hurdlers (Mean \pm SD).

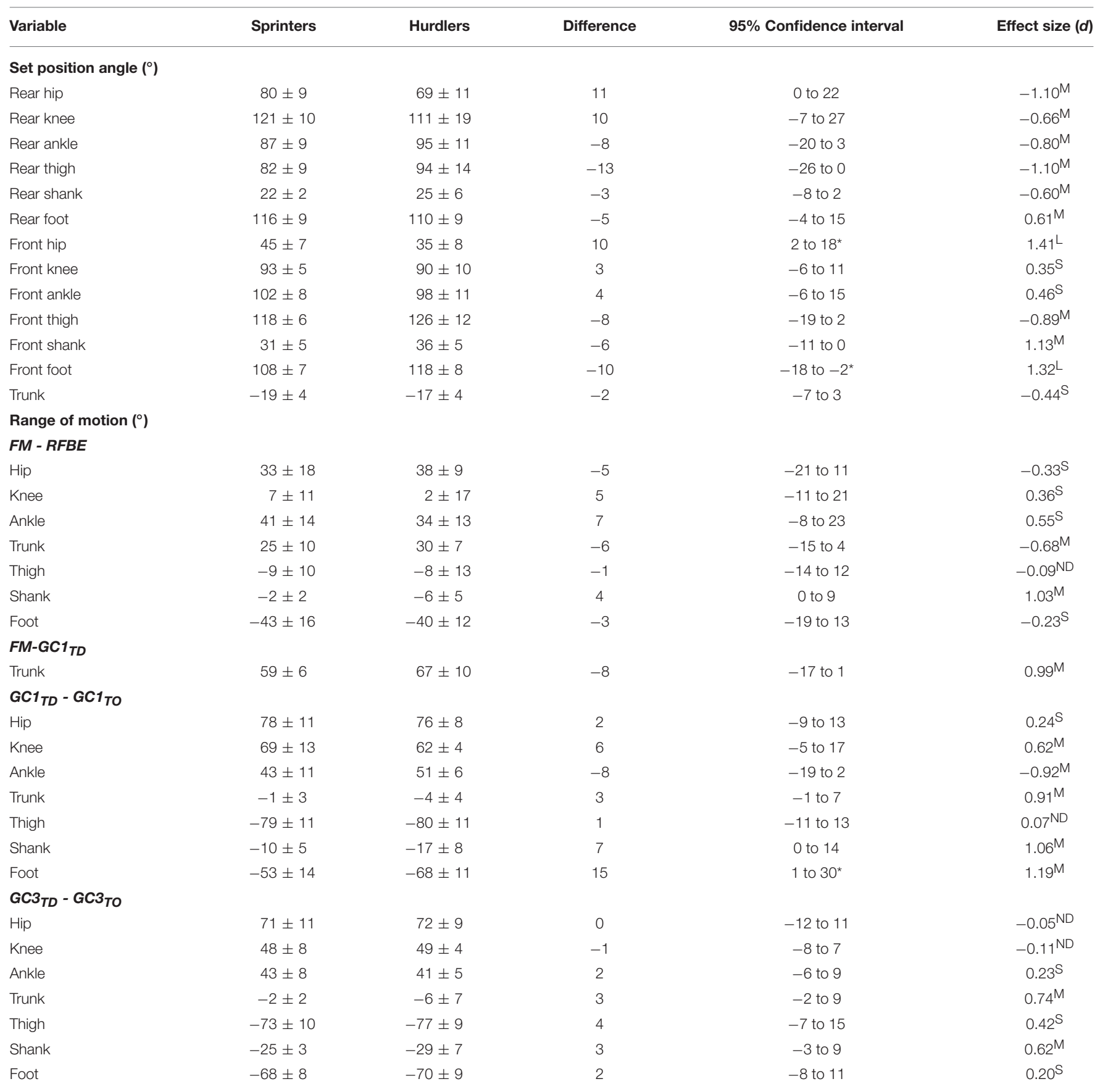

Differences are calculated as sprinters minus hurdlers, so negative values represent values for hurdlers being greater than sprinters. *Represents where the confidence interval for the between group comparison does not cross zero (Altman and Gardner, 2000). Effect size scale (Hopkins et al., 2009): No Difference (ND) $=<0.20$; Small (S) $=\geq 0.20$ to $<0.60$; Moderate $(M)=\geq 0.60<1.20$; Large $(L)=\geq 1.20$ to $<2.00$; Very Large $(N L)=\geq 2.00$ to $<4.00$; Extremely Large $(E L)=\geq 4.00$.

leading to longer push-phase times, the absolute positioning of the blocks from the start line has received little attention in the biomechanics research literature (Schot and Knutzen, 1992). Coaching literature has identified that hurdlers tend to place starting blocks closer to the start line than sprinters, but that this has negative consequences for performance (Mann and Murphy, 2018). In this study, the hurdlers' medium block spacing combined with the front block being closer to the start line (Table 1) led to relatively more flexed hip angles in the set position (front hip difference $10^{\circ}, 2$ to 18 , large effect; rear hip difference $11^{\circ}, 0$ to 22, medium effect; Figure 4, Table 3). The net effect would have led to a greater extensor angular velocity of the front hip in the hurdlers, particularly during the single-leg push phase (Slawinski et al., 2013), which therefore 

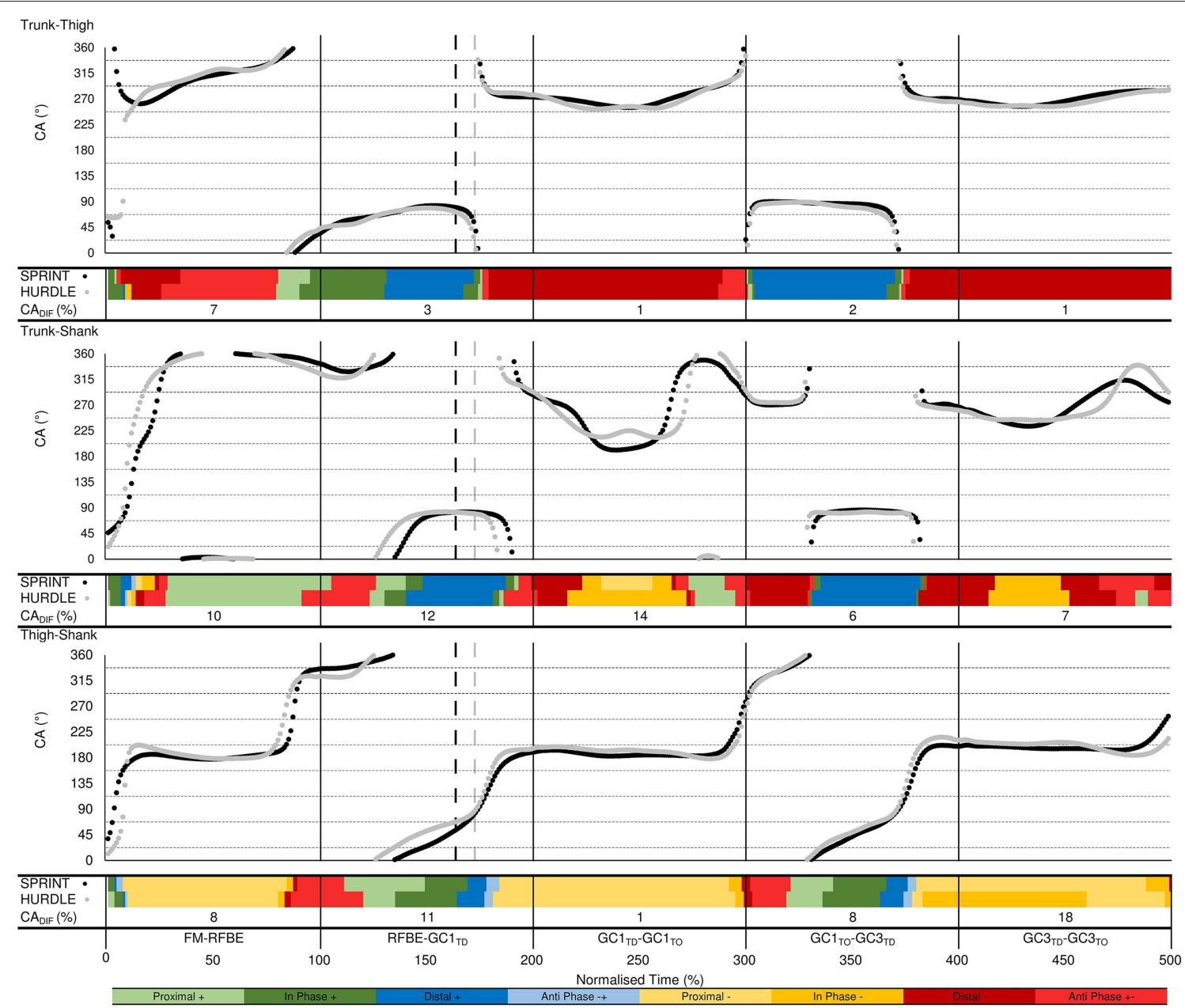

FIGURE 10 | Trunk-thigh (top), trunk-shank (middle), and thigh-shank (bottom) coupling angle-normalised time profiles for the sprint (black dots) and hurdle (grey dots) groups throughout each key phase of start and initial acceleration related to the rear leg in the blocks. Colour profiles represent coupling angle classification at each instance across the normalised time cycle (see Figure 3B). The overall difference score (CADIF) in coordination patterns between the sprint and hurdle groups is shown beneath each colour profile. Group mean instances of FFBE are indicated by black (sprint) and grey (hurdle) vertical dashed lines.

would have increased the vertical displacement of the CM and shoulder joint centres (Figures 6A, 7A, respectively) more so in the hurdlers than sprinters. Analysis of trunk-thigh couples in the block phase showed an earlier onset of anti phase (+-) coordination (Figure 10), supporting the finding that hurdlers started to raise their trunk and CM earlier in the block phase than sprinters. Indeed, the biggest differences seen in the raising of the CM between hurdlers and sprinters occurred during the block phase, and likely come as a direct consequence of the differences in body orientations in the set position.

During the double-leg push phase the hurdlers as a group were clearly more variable than the sprinters in the amount that they raised the CM, and hip and knee joint centres, but clearly less variable in the amount that they raised their shoulder joint centre (Figures 6, 7). This suggests a more variable response in the lower limb within the hurdlers, between different athletes, and highlights individual variations in the responses to the task. It is important for coaches to note that despite the consistent extent to which the hurdlers raised their shoulders during the double leg push phase, the manner in which this was controlled by the distal segments was much more variable.

Continuous segmental data (Figures 4, 8, 9) revealed that the hurdlers had more vertically orientated trunk and shank segments, and more horizontally orientated foot segments, than sprinters for periods in late swing and early stance around both $\mathrm{GC1}_{\mathrm{TD}}$ and $\mathrm{GC} 3_{\mathrm{TD}}$. At each of the subsequent take-off events the differences in trunk, shank and foot angles between hurdlers and sprinters, whilst still clear, had reduced in magnitude (Figure 9). It therefore appears that these differences tend to accumulate during the longer flight phases in the hurdlers (Table 1), but then during the ground contact phases the hurdlers bring their segment orientations back towards those adopted by the sprinters (Figure 9). It is likely that the differences in segment angles combined with the greater stature of the hurdlers combine to provide the visual impression of a more upright stance in the hurdlers, particularly at touchdown events. 


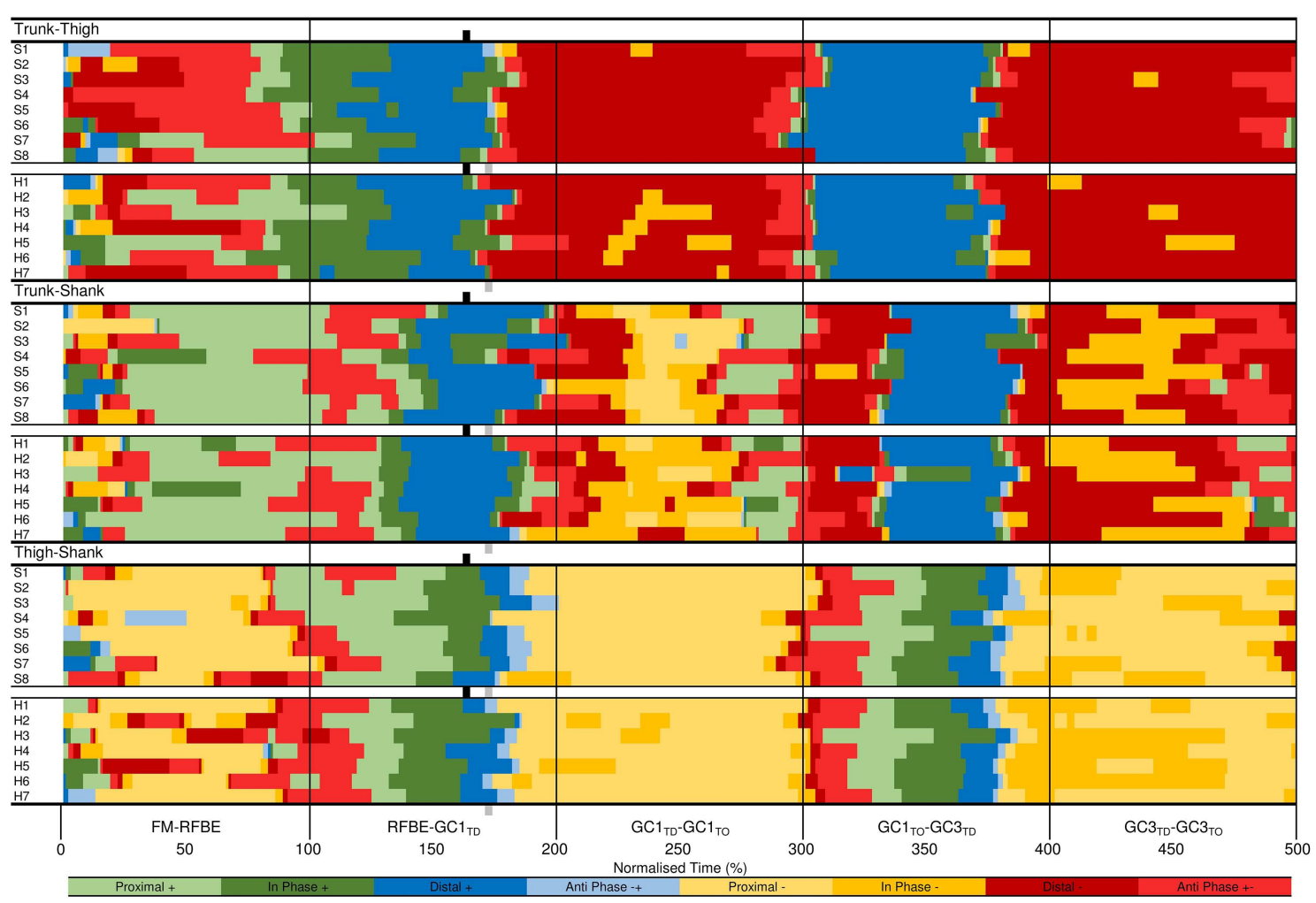

FIGURE 11 | Individual coordination profiles for the trunk-thigh (top), trunk-shank (middle), and thigh-shank (bottom) couples, throughout each key phase of start and initial acceleration related to the rear leg in the blocks. Colour profiles represent coupling angle classification at each instance across the normalised time cycle (see Figure 3B). Group mean instances of FFBE are indicated by black (sprint) and grey (hurdle) shading surrounding each group of individual athletes.

One key novel aspect of the current study was the complimentary nature of both qualitative and quantitative analysis of coordination, utilising popular 'binning' approaches (Silvernail et al., 2018) to visualise local and global similarities and differences in inter-segmental coordination in this unique sample of world-class athletes. The largest inter-group and interindividual differences in coordination were observed soon after FM. As coordination variability has been shown to increase during changes to the state of the system (Heiderscheit et al., 2002), it could be theorised that the abrupt state change at FM contributed to the observed inter-group and inter-individual differences. In addition, the differences in the set position between athletes might have dictated initial coordination of the system, as shown by Gheller et al. (2015) who found that starting knee angle influenced coordination patterns during vertical jumps. The reduction in inter-individual differences after the initial part of the double-leg push phase could be indicative of self-organisation towards task-specific coordinative structures (Newell, 1986). However, it should be recognised that artefacts when consecutive data points are in close proximity (Heiderscheit et al., 2002) could also have influenced the initial inter-group and inter-individual differences in coordination at this early stage of the movement.

The nature of the data presented in this study, captured in situ in the world's best sprinters and hurdlers during the finals of the IAAF World Indoor Championships ensured that the ecological validity of the analysis conducted here was maintained in an exceptional manner. Indeed, the $60 \mathrm{~m}$ final included three of the fastest twenty times run in the history of the event. The very nature of this maintenance of ecological validity means that the sample sizes were small. However, the populations of the very best athletes in the world in any individual event are by definition small, and this study provides a comprehensive analysis of the mechanisms for the translation of the $\mathrm{CM}$ in this world-class sample. In doing so, it therefore addresses a significant gap in the biomechanics research literature. Further, studies of sprint hurdle biomechanics have generally focused on the hurdle clearance and three-step inter-hurdle cycle (e.g., Mann and Herman, 1985a; McDonald and Dapena, 1991; Salo et al., 1997). To the authors' knowledge this is the first study that has investigated the start and initial acceleration phase in elite high hurdlers, as well as being the first to apply coordination analyses to the start and initial acceleration phase of a sprint. Data presented here have shown that the biggest differences in the raising of the CM occurred during the single-leg push phase in the blocks. Future research should therefore additionally consider the role of the front leg in the blocks, that might reveal interesting additional insights into the mechanisms utilised by sprinters and hurdlers.

\section{Coaching Implications}

The similarities that were shown between the sprinters and hurdlers, despite the differing task constraints being faced by 
the athletes, were the most striking feature of this analysis. Overall, the response to the task to accelerate the $\mathrm{CM}$ in a horizontal direction was primarily the same across the two events, which challenges current thinking. The key differences that did occur came primarily from the initial body positions in the set position, so there should be some consideration for an individual approach to block set up by coaches and athletes. Once the push phase in the blocks began, there was clearly a relatively common pattern of coordination across all athletes. This overall consistent organisation of movement during the start and initial acceleration phase is an important consideration for coaches, and needs to be maintained even when accounting for individual factors that may influence performance such as stature or strength. The hurdlers as a group were more variable than sprinters in the manner in which they raised their lower body segments in the block phase, but then also used the following ground contact phases to converge their segment orientations back towards those adopted by the sprinters. It may therefore be that small visual differences in orientations that might be apparent at touchdown events should not be of major concern, and are typically overcome by hurdlers during the subsequent ground contact phase.

The fact that all seven hurdlers studied here chose to adopt a seven-step approach to the first hurdle meant that a direct comparison of the differences between seven- and eight-step approaches was not possible. Additional work is no doubt required to address the implications of any differences between these two approach strategies. Nonetheless, the data presented here provides an important underpinning to the coaching literature, and reveals that even when high-hurdlers adopt a seven-step approach to the first hurdle, there are many similarities between the techniques they adopt and those of their sprint counterparts.

\section{CONCLUSION}

This novel study was successful firstly in quantifying and explaining the start and initial acceleration technique of the world's best male sprinters and hurdlers in situ in an elite competition environment, and secondly in elucidating the similarities in the mechanisms by which sprinters and hurdlers translate their CM during the start and initial acceleration phases. Coordination patterns adopted by sprinters and hurdlers were similar throughout the start and initial acceleration phases, and differences in $\mathrm{CM}$ raising generally occurred as a result of small differences that were present from block set-up. This study has generated an exceptional and significant data set, and the analysis presented here will become a primary source of

\section{REFERENCES}

Abdel-Aziz, Y. I., and Karara, H. M. (1971). Direct Linear Transformation From Comparator Coordinates Into Object Space Coordinates in Close-Range Photogrammetry. Falls Church, VA: American Society of Photogrammetry.

Altman, D. G., and Gardner, M. J. (2000). "Means and their difference," in Statistics With Confidence, eds D. G. Altman, D. Machin, T. N. Bryant, and M. J. Gardner (London: BMJ Books), 28-35. reference for those wanting to further explore the start and initial acceleration phase in both sprinters and hurdlers as a means of optimising performance. The findings from this study contribute new conceptual understanding of the mechanisms that underpin start and initial acceleration performance for scientists, coaches and athletes.

\section{DATA AVAILABILITY}

The datasets generated for this study will not be made publicly available in order to avoid identifying individual athletes.

\section{ETHICS STATEMENT}

The studies involving human participants were reviewed and approved by (1) IAAF obtained signed Athlete Acknowledgment and Agreement Forms from the athletes to use their moving images. (2) The study was approved by the Leeds Beckett University Ethics sub-committee (School local approval by Research Ethics Coordinator). The patients/participants provided their written informed consent to participate in this study.

\section{AUTHOR CONTRIBUTIONS}

IB, ABr, HL, GP, SM, P-JV, JW, and ABi conceived and designed the study. GP, BH, CT, LP, JW, and ABi performed data collection. $\mathrm{IB}, \mathrm{ABr}, \mathrm{HL}, \mathrm{BH}, \mathrm{CT}, \mathrm{LP}, \mathrm{JW}$, and $\mathrm{ABi}$ processed data. IB, ABr, HL, $\mathrm{MW}, \mathrm{GP}, \mathrm{JW}$, and $\mathrm{ABi}$ interpreted the results of the research. IB and $\mathrm{ABr}$ drafted the manuscript. $\mathrm{IB}, \mathrm{ABr}$, and $\mathrm{HL}$ prepared tables and figures. IB, ABr, HL, MW, GP, BH, CT, LP, SM, P-JV, JW, and $\mathrm{ABi}$ edited, critically revised, and approved the final version for submission.

\section{FUNDING}

The data collection and initial data analysis were supported by funding provided by the IAAF as part of a wider development/education project, however, this particular article has not been supported by any particular and specific funding source.

\section{ACKNOWLEDGMENTS}

The authors would like to thank Professor Lynne Evans for her advice regarding the preparation of the manuscript and Professor Stephen-Mark Cooper for his advice regarding the statistical analysis of the data.

Bahamonde, R. E., and Stevens, R. R. (2006). Comparison of Two Methods of Manual Digitization on Accuracy and Time of Completion. Salzburg, Austria: ISBS.

Bernstein, N. (1967). The Coordination and Regulation of Movements. Oxford: Pergamon.

Bezodis, I. N., Kerwin, D. G., Cooper, S. M., and Salo, A. I. T. (2018). Sprint running performance and technique changes in athletes during periodized training: an elite training group case study. Int. 
J. Sports Physiol. Perform. 13, 755-762. doi: 10.1123/ijspp.20170378

Bezodis, I. N., Kerwin, D. G., and Salo, A. I. T. (2008). Lower-limb mechanics during the support phase of maximum-velocity sprint running. Med. Sci. Sports Exerc. 40, 707-715. doi: 10.1249/MSS.0b013e318162d162

Bezodis, N. E., Salo, A. I. T., and Trewartha, G. (2014). Lower limb joint kinetics during the first stance phase in athletics sprinting: three elite athlete case studies. J. Sports Sci. 32, 738-746. doi: 10.1080/02640414.2013.849000

Bezodis, N. E., Salo, A. I. T., and Trewartha, G. (2015). Relationships between lower-limb kinematics and block phase performance in a cross section of sprinters. Eur. J. Sport Sci. 15, 118-124. doi: 10.1080/17461391.2014.928915

Bezodis, N. E., Walton, S. P., and Nagahara, R. (2019a). Understanding the track and field sprint start through a functional analysis of the external force features which contribute to higher levels of block phase performance. J. Sports Sci. 37, 560-567. doi: 10.1080/02640414.2018.1521713

Bezodis, N. E., Willwacher, S., and Salo, A. I. T. (2019b). The Biomechanics of the track and field sprint start: a narrative review. Sports Med. 49, 1345-1364. doi: 10.1007/s40279-019-01138-1

Bissas, A., Walker, J., Tucker, C., Paradisis, G., and Merlino, S. (2018). "Biomechanical report for the IAAF world championships 2017: 100 m Men's," in 2017 IAAF World Championships Biomechanics Research Project (London: International Association of Athletics Federations).

Brazil, A., Exell, T., Wilson, C., Willwacher, S., Bezodis, I., and Irwin, G. (2017). Lower limb joint kinetics in the starting blocks and first stance in athletic sprinting. J. Sports Sci. 35, 1629-1635. doi: 10.1080/02640414.2016.1227465

Brazil, A., Exell, T., Wilson, C., Willwacher, S., Bezodis, I. N., and Irwin, G. (2018). Joint kinetic determinants of starting block performance in athletic sprinting. J. Sports Sci. 36, 1656-1662. doi: 10.1080/02640414.2017.1409608

Chang, R., Van Emmerik, R., and Hamill, J. (2008). Quantifying rearfootforefoot coordination in human walking. J. Biomech. 41, 3101-3105. doi: 10.1016/j.jbiomech.2008.07.024

Charalambous, L., Irwin, G., Bezodis, I. N., and Kerwin, D. (2012). Lower limb joint kinetics and ankle joint stiffness in the sprint start push-off. J. Sports Sci. 30, 1-9. doi: 10.1080/02640414.2011.616948

Ciacci, S., Merni, F., Bartolomei, S., and Di Michele, R. (2017). Sprint start kinematics during competition in elite and world-class male and female sprinters. J. Sports Sci. 35, 1270-1278. doi: 10.1080/02640414.2016.1221519

Coh, M., Peharec, S., and Bacic, P. (2007). The sprint start: biomechanical analysis of kinematic, dynamic and electromyographic parameters. New Stud. Athletics 22, 29-38.

de Leva, P. (1996). Adjustments to Zatsiorsky-Seluyanov's segment inertia parameters. J. Biomech. 29, 1223-1230.

Debaere, S., Delecluse, C., Aerenhouts, D., Hagman, F., and Jonkers, I. (2013). From block clearance to sprint running: characteristics underlying an effective transition. J. Sports Sci. 31, 137-149. doi: 10.1080/02640414.2012.722225

Floría, P., Sánchez-Sixto, A., Harrison, A. J., and Ferber, R. (2019). The effect of running speed on joint coupling coordination and its variability in recreational runners. Hum. Mov. Sci. 66, 449-458. doi: 10.1016/j.humov.2019.05.020

Fortier, S., Basset, F. A., Mbourou, G. A., Faverial, J., and Teasdale, N. (2005). Starting block performance in sprinters: a statistical method for identifying discriminative parameters of the performance and an analysis of the effect of providing feedback over a 6-week period. J. Sports Sci. Med. 4, 134-143. Available online at: https://www.jssm.org/hf.php?id=jssm-04-134.xml

Freeman, W. (2015). Track \& Field Coaching Essentials: USA Track \& Field Level 1 Coach Education Manual. Champaign, IL: Human Kinetics.

Gheller, R. G., Dal Pupo, J., Ache-Dias, J., Detanico, D., Padulo, J., and dos Santos, S. G. (2015). Effect of different knee starting angles on intersegmental coordination and performance in vertical jumps. Hum. Mov. Sci. 42, 71-80. doi: 10.1016/j.humov.2015.04.010

Gittoes, M. J. R., and Wilson, C. (2010). Intralimb joint coordination patterns of the lower extremity in maximal velocity phase sprint running. J. Appl. Biomech. 26, 188-195. doi: 10.1123/jab.26.2.188

Hamill, J., van Emmerik, R. E. A., Heiderscheit, B. C., and Li, L. (1999). A dynamical systems approach to lower extremity running injuries. Clin. Biomech. 14, 297-308.

Heiderscheit, B. C., Hamill, J., and van Emmerik, R. E. A. (2002). Variability of stride characteristics and joint coordination among individuals with unilateral patellofemoral pain. J. Appl. Biomech. 18, 110-121. doi: 10.1123/jab.18.2.110
Henry, F. M. (1952). Force-time characteristics of the sprint start. Res. Q. 23, 301-318.

Hopkins, W. G., Marshall, S. W., Batterham, A. M., and Hanin, J. (2009). Progressive statistics for studies in sports medicine and exercise science. Med. Sci. Sports Exerc. 41, 3-12. doi: 10.1249/MSS.0b013e31818cb278

Kugler, F., and Janshen, L. (2010). Body position determines propulsive forces in accelerated running. J. Biomech. 43, 343-348. doi: 10.1016/j.jbiomech.2009.07.041

Mann, R. V., and Herman, J. (1985a). Kinematic analysis of olympic hurdle performance: women's 100 meters. Int. J. Sport Biomech. 1, 163-173.

Mann, R. V., and Herman, J. (1985b). Kinematic analysis of olympic sprint performance: men's 200 meters. Int. J. Sport Biomech. 1, 151-162.

Mann, R. V., and Murphy, A. (2018). The Mechanics of Sprinting and Hurdling. Las Vegas, NV.

McDonald, C., and Dapena, J. (1991). Linear kinematics of the men's 110-m and women's 100-m hurdles races. Med. Sci. Sports Exerc. 23, 1382-1391.

Morin, J. B., Bourdin, M., Edouard, P., Peyrot, N., Samozino, P., and Lacour, J. R. (2012). Mechanical determinants of 100-m sprint running performance. Eur. J. Appl. Physiol. 112, 3921-3930. doi: 10.1007/s00421-012-2379-8

Morin, J. B., Edouard, P., and Samozino, P. (2011). Technical ability of force application as a determinant factor of sprint performance. Med. Sci. Sports Exerc. 43, 1680-1688. doi: 10.1249/MSS.0b013e318216ea37

Nagahara, R., Matsubayashi, T., Matsuo, A., and Zushi, K. (2014). Kinematics of transition during human accelerated sprinting. Biol. Open. 3, 689-699. doi: 10.1242/bio.20148284

Needham, R., Naemi, R., and Chockalingam, N. (2014). Quantifying lumbar-pelvis coordination during gait using a modified vector coding technique. J. Biomech. 47, 1020-1026. doi: 10.1016/j.jbiomech.2013.12.032

Newell, K. M. (1986). "Constraints on the development of coordination," in Motor Development in Children. Aspects of Coordination and Control, eds M. G. Wade and H. T. A. Whiting (Dordrecht: Martinus Nijhoff), 341-360.

Pollitt, L., Walker, J., Bissas, A., and Merlino, S. (2018). "Biomechanical report for the IAAF world championships 2017: 110 m Hurdles Men's," in 2017 IAAF World Championships Biomechanics Research Project (London: International Association of Athletics Federations).

Rabita, G., Dorel, S., Slawinski, J., Sàez-de-Villarreal, E., Couturier, A., Samozino, P., et al. (2015). Sprint mechanics in world-class athletes: a new insight into the limits of human locomotion. Scand. J. Med. Sci. Sports 25, 583-594. doi: $10.1111 /$ sms. 12389

Rash, G. S., Garrett, J., and Viosin, M. (1990). Kinematic analysis of top American female 100-meter hurdlers. Int. J. Sport Biomech. 6, 386-393.

Salo, A., Grimshaw, P. N., and Marar, L. (1997). 3-D biomechanical analysis of sprint hurdles at different competitive levels. Med. Sci. Sports Exerc. 29, 231-237.

Salo, A. I. T., Bezodis, I. N., Batterham, A. M., and Kerwin, D. G. (2011). Elite sprinting: are athletes individually step-frequency or step-length reliant? Med. Sci. Sports Exerc. 43, 1055-1062. doi: 10.1249/MSS.0b013e3182 $0166 f 8$

Schot, P. K., and Knutzen, K. M. (1992). A biomechanical analysis of four sprint start positions. Res. Q. Exerc. Sport 63, 137-147.

Silvernail, J. F., van Emmerik, R. E. A., Boyer, K., Busa, M. A., and Hamill, J. (2018). Comparisons of segment coordination: an investigation of vector coding. $J$. Appl. Biomech. 34, 226-231. doi: 10.1123/jab.2017-0081

Slawinski, J., Dumas, R., Cheze, L., Ontanon, G., Miller, C., and Mazure-Bonnefoy, A. (2012). 3D Kinematic of bunched, medium and elongated sprint start. Int. J. Sports Med. 33, 555-560. doi: 10.1055/s-0032-1304587

Slawinski, J., Dumas, R., Cheze, L., Ontanon, G., Miller, C., and MazureBonnefoy, A. (2013). Effect of postural changes on 3D joint angular velocity during starting block phase. J. Sports Sci. 31, 256-263. doi: 10.1080/02640414.2012.729076

Slawinski, J., Termoz, N., Rabita, G., Guilhem, G., Dorel, S., Morin, J. B., et al. (2017). How 100-m event analyses improve our understanding of world-class men's and women's sprint performance. Scand. J. Med. Sci. Sports 27, 45-54. doi: 10.1111/sms.12627

Sparrow, W. A., Donovan, E., van Emmerik, R., and Barry, E. B. (1987). Using relative motion plots to measure changes in intralimb and inter-limb coordination. J. Mot. Behav. 19, 115-129. doi: 10.1080/00222895.1987.10735403 
Taylor, M. J. D., and Beneke, R. (2012). Spring mass characteristics of the fastest men on earth. Int. J. Sports Med. 33, 667-670. doi: 10.1055/s-0032-1306283

Turvey, M. T. (1990). Coordination. Am. Psychol. 45, 938-953.

von Lieres und Wilkau, H. C., Irwin, G., Bezodis, N. E., Simpson, S., and Bezodis, I. N. (2018). Phase analysis in maximal sprinting: an investigation of step-to-step technical changes between the initial acceleration, transition and maximal velocity phases. Sports Biomech. doi: 10.1080/14763141.2018. 1473479. [Epub ahead of print].

Walker, J., Pollitt, L., Paradisis, G., Bezodis, I., Bissas, A., and Merlino, S. (2019a). Biomechanical Report for the IAAF World Indoor Championships 2018: 60 Metres Hurdles Men. Birmingham: International Association of Athletics Federations.

Walker, J., Tucker, C. B., Paradisis, G. P., Bezodis, I., Bissas, A., and Merlino, S. (2019b). Biomechanical Report for the IAAF World Indoor Championships 2018: 60 Metres Men. Birmingham: International Association of Athletics Federations.

Wild, J. J., Bezodis, I. N., North, J. S., and Bezodis, N. E. (2018). Differences in step characteristics and linear kinematics between rugby players and sprinters during initial sprint acceleration. Eur. J. Sport Sci. 18, 1327-1337. doi: $10.1080 / 17461391.2018 .1490459$
Willwacher, S., Herrmann, V., Heinrich, K., Funken, J., Strutzenberger, G., Goldmann, J. P., et al. (2016). Sprint start kinetics of amputee and non-amputee sprinters. PLoS ONE 11:e0166219. doi: 10.1371/journal.pone.0166219

Winter, D. A. (2009). Biomechanics and Motor Control of Human Movement. Hoboken, NJ: John Wiley and Sons, Inc.

Conflict of Interest Statement: $\mathrm{ABi}$ is the Director of Athletics Biomechanics.

The remaining authors declare that the research was conducted in the absence of any commercial or financial relationships that could be construed as a potential conflict of interest.

Copyright (c) 2019 Bezodis, Brazil, von Lieres und Wilkau, Wood, Paradisis, Hanley, Tucker, Pollitt, Merlino, Vazel, Walker and Bissas. This is an open-access article distributed under the terms of the Creative Commons Attribution License (CC BY). The use, distribution or reproduction in other forums is permitted, provided the original author(s) and the copyright owner(s) are credited and that the original publication in this journal is cited, in accordance with accepted academic practice. No use, distribution or reproduction is permitted which does not comply with these terms. 